University of Louisville

ThinkIR: The University of Louisville's Institutional Repository

$5-2005$

\title{
A cross sectional analysis of the relationship between childhood obesity and craniofacial dimensions in a population receiving orthodontic treatment.
}

Daniel Mark Eves

University of Louisville

Follow this and additional works at: https://ir.library.louisville.edu/etd

\section{Recommended Citation}

Eves, Daniel Mark, "A cross sectional analysis of the relationship between childhood obesity and craniofacial dimensions in a population receiving orthodontic treatment." (2005). Electronic Theses and Dissertations. Paper 414.

https://doi.org/10.18297/etd/414

This Master's Thesis is brought to you for free and open access by ThinkIR: The University of Louisville's Institutional Repository. It has been accepted for inclusion in Electronic Theses and Dissertations by an authorized administrator of ThinkIR: The University of Louisville's Institutional Repository. This title appears here courtesy of the author, who has retained all other copyrights. For more information, please contact thinkir@louisville.edu. 


\title{
A CROSS SECTIONAL ANALYSIS OF THE RELATIONSHIP BETWEEN CHILDHOOD OBESITY AND CRANIOFACIAL DIMENSIONS IN A POPULATION RECEIVING ORTHODONTIC TREATMENT
}

\author{
By \\ Daniel M. Eves \\ B.S., United States Naval Academy, 1986 \\ M.B.A., Providence College, 1995 \\ D.M.D., University of Florida, 1999
}
A Thesis
Submitted to the Faculty of the
Graduate School of the University of Louisville
In Partial Fulfillment of the Requirements
For the Degree of

Masters of Science in Oral Biology

Department of Orthodontics and Pediatric Dentistry

University of Louisville

Louisville, KY

May 2005 
A CROSS SECTIONAL ANALYSIS OF THE RELATIONSHIP BETWEEN CHILDHOOD OBESITY AND CRANIOFACIAL DIMENSIONS IN A POPULATION RECEIVING ORTHODONTIC TREATMENT

\section{By}

Daniel M. Eves

B.S., United States Naval Academy, 1986

M.B.A., Providence College, 1995

D.M.D., University of Florida, 1999

A Thesis Approved on

April 7, 2005

By the following Thesis Committee:

Thesis Director 


\section{DEDICATION}

This thesis is dedicated to my parents

who have always been there when I needed support and guidance, and to my family whom I love and treasure dearly. 


\section{ACKNOWLEDGEMENTS}

I would like to thank my thesis committee members, Dr. Kelly Hilgers, Dr. Ed

Johnson, and Dr. James Scheetz for their guidance and support. 


\section{ABSTRACT \\ A CROSS SECTIONAL ANALYSIS OF THE RELATIONSHIP BETWEEN CHILDHOOD OBESITY AND CRANIOFACIAL DIMENSIONS IN A POPULATION RECEIVING ORTHODONTIC TREATMENT \\ Daniel M. Eves, D.M.D.}

April 7, 2005

The purpose of this study was to determine if obesity impacts craniofacial dimensions in adolescent and teenage subjects.

Twenty-one cephalometric measurements were selected as a basis for comparison between normal weight, overweight and obese children. The subjects were weighed, measured, and placed into one of the three groups based on their Body Mass Index (BMI). Lateral cephalometric radiographs were taken, traced and digitized on all patients. The various measurements were analyzed to determine if there were any statistically significant differences between any of the measurements when compared on the basis of BMI.

The following seven measurements showed a statistically significant difference when evaluated on the basis of BMI: SNA, maxillary unit length, $\mathrm{SNB}$, corpus length, mandibular unit length, soft tissue convexity and soft tissue facial height ratio. Comparisons were also made on the basis of gender and age. Three of the measurements for gender showed a statistically significant difference: S-N, maxillary unit length and mandibular unit length. Similarly, three of the 
measurements for age showed a statistically significant difference: maxillary unit length, corpus length and mandibular unit length. 


\section{TABLE OF CONTENTS}

PAGE

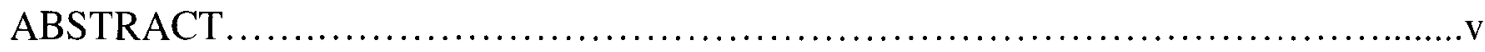

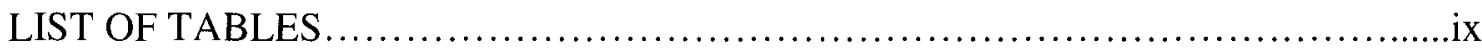

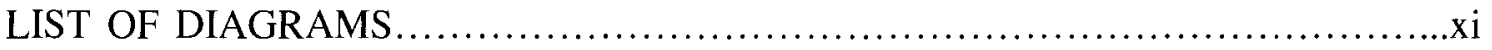

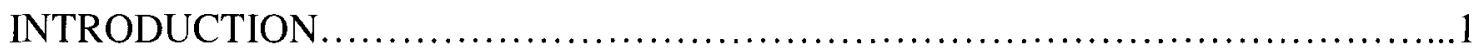

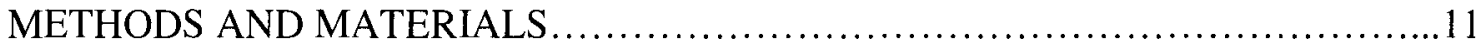

BMI computation................................................. 12

Description of Measurements............................................15

Age Groups Defined.......................................................

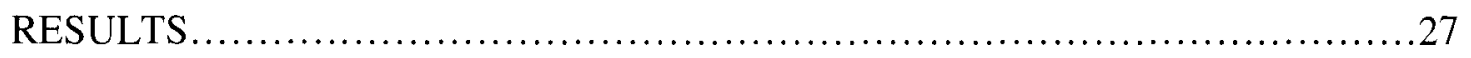

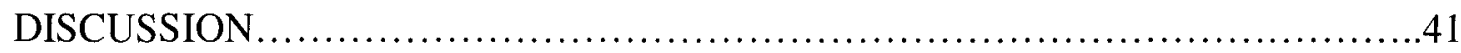

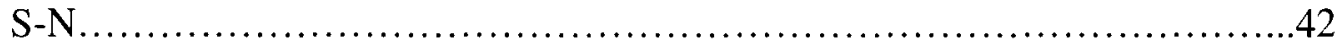

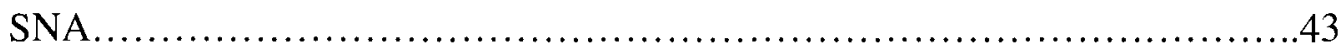

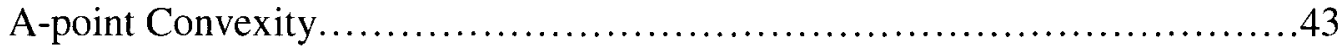

Maxillary Unit Length................................................43

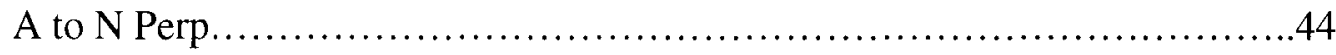

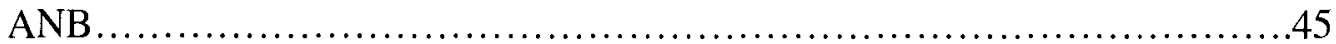

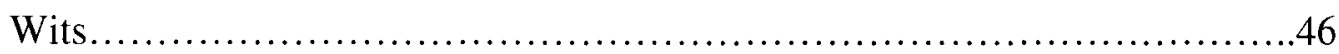

Facial Axis................................................................... 
SNB

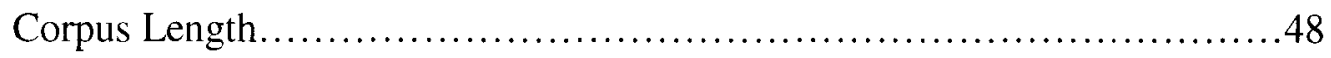

Mandibular Unit Length..............................................48

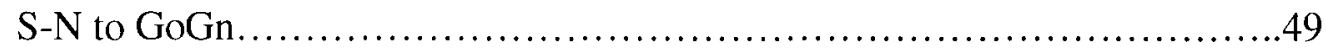

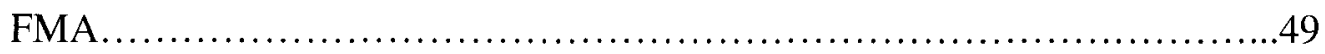

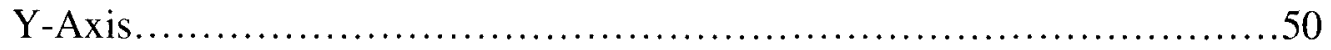

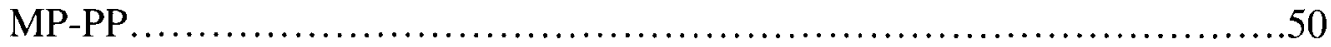

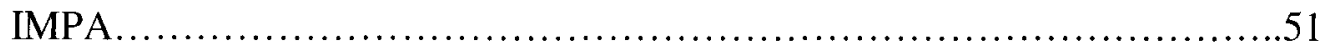

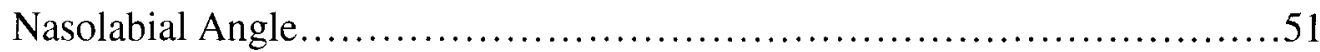

Chin Throat Angle .....................................................52

Soft Tissue Convexity ...............................................52

Soft Tissue Facial Height Ratio...........................................53

Lower Lip to E-Plane............................................5

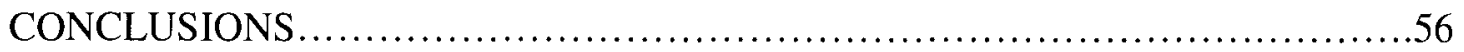

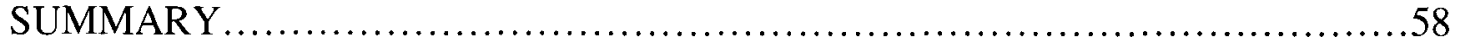

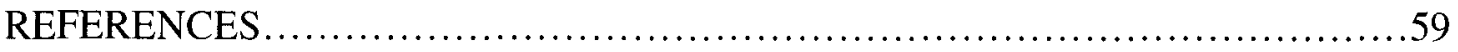

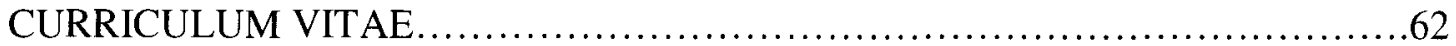




\section{LIST OF TABLES}

TABLE

PAGE

1. Description of Anatomical Points....................................... 14

2. Number of Patients Exhibiting Each of the Independent Variable Evaluated.....

3. Mean, Norm and Standard Deviations for Selected

Craniofacial Dimensions. .28

4. Variables Affecting Mean Craniofacial Measurements

for varying BMI's

5. Variables Affecting Mean Craniofacial Measurements for varying BMI's 31

6. Variables Affecting Mean Craniofacial Measurements for varying BMI's

7. Variables Affecting Mean Craniofacial Measurements for Males and Females. 34

8. Variables Affecting Mean Craniofacial Measurements for Males and Females. 35

9. Variables Affecting Mean Craniofacial Measurements for Males and Females. 36 
10. Variables Affecting Mean Craniofacial Measurements for

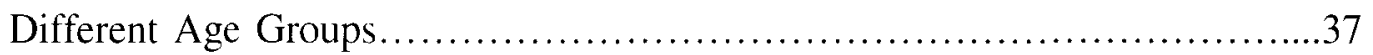

11. Variables Affecting Mean Craniofacial Measurements for

Different Age Groups.....................................................

12. Variables Affecting Mean Craniofacial Measurements for

Different Age Groups....................................................40 


\section{LIST OF DIAGRAMS}

\section{DIAGRAM}

PAGE

1. Illustration of the Anatomical Points used in this Study .......................13

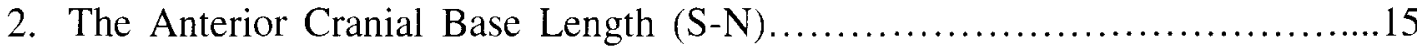

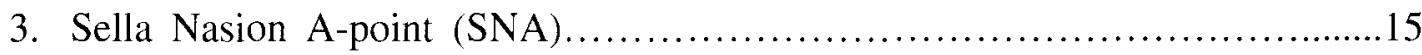

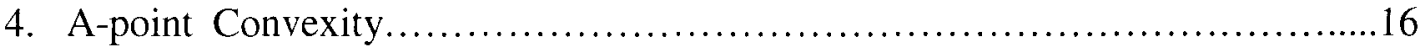

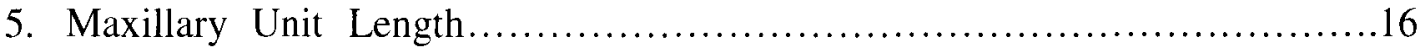

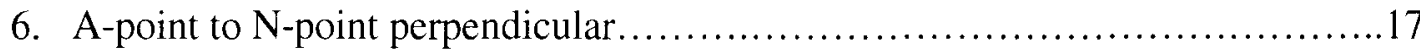

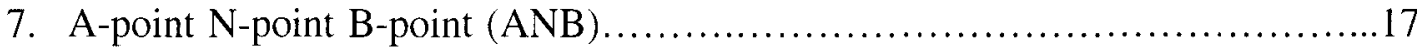

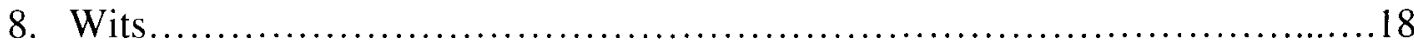

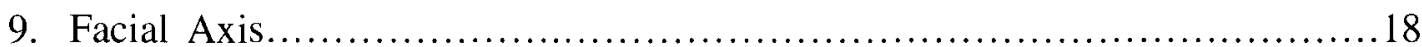

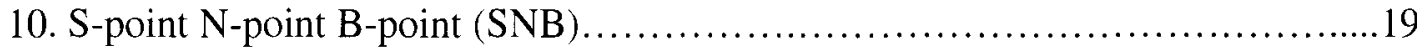

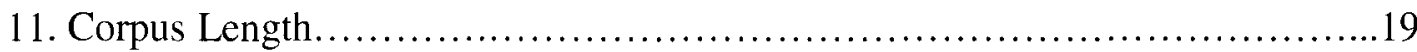

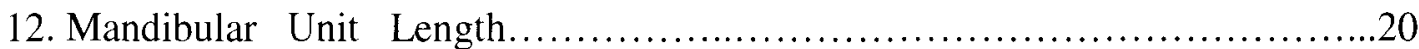

13. Sella-Nasion to Gonion-Gnathion (S-N to Go-Gn) .........................20

14. Frankfort Mandibular Plane Angle (FMA) .................................

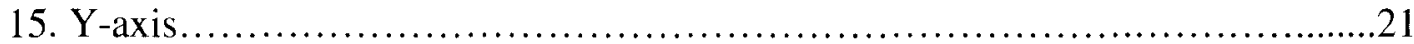

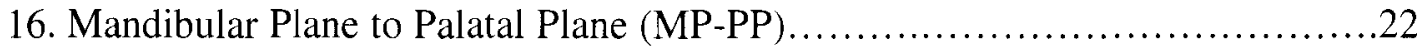

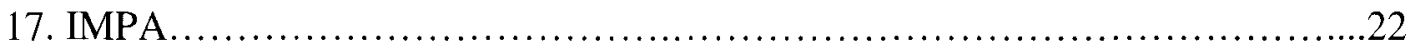

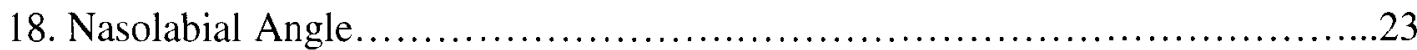




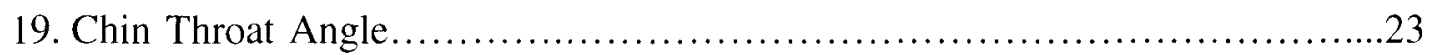

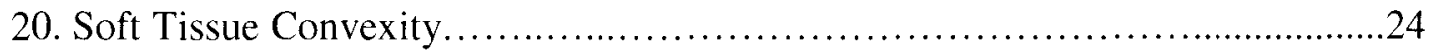

21. Soft Tissue Facial Height Ratio..........................................24

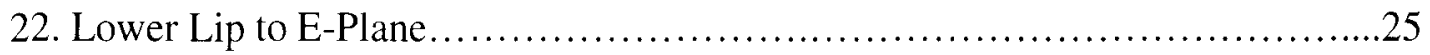




\section{INTRODUCTION}

Obesity in the United States is an ever increasing health problem. In particular, childhood obesity continues to increase at an alarming pace presently reaching epidemic proportions. In 1960, the National Health and Nutrition Examination (NHNE) Survey documented that the childhood obesity level was 5\%, between 1988 and 1994 it was documented at $11 \%$, and the $1999-2000$ NHNE survey reported the childhood obesity rate at $15 \%$. This increase was seen predominantly in particular ethnic groups, such as African Americans and Mexican Americans. Obesity increased in these groups 10\% between the 1988 - 1994 survey and the $1999-2000$ survey, but only increased by $5 \%$

during the same time span in Caucasian children.[1] The results of a more recent obesity study conducted on elementary school children in New York City are even more alarming. In May 2003, 43\% of the 2,681 children measured were overweight and 24\% were obese. Thirty-one percent of Hispanic children, 23\% of African American children, $16 \%$ of Caucasian children and $14 \%$ of Asian children were determined to be obese.[1]

The suspected causes for this rapid rise in childhood obesity are multi-factorial, and each of the factors has the potential to arise during childhood. Genetic mutation is one factor. For example, two grossly obese Pakistani children were born to normal parents and were later identified as having genetic mutations. A total of five mutations were identified as contributing to their obesity. Among these mutations is one that 
encodes for leptin, a hormone that is secreted by adipocytes and is found at levels consistent with the amount of body fat present.[2] Additional factors contributing to obesity include the lack of physical activity and increasingly sedentary lifestyles. According to a study conducted by Ebbeling, (2002) excessive television watching appears to be the most significant factor contributing to the lack of childhood physical activity. Not only does television viewing decrease the amount of time spent in physical activity, but it often leads to an increase in the amount of calories consumed as viewing food commercials on TV may increase appetite and influence poorer food selection.[2]

Diet has also dramatically changed over the last forty years and is a significant contributor to the increase in childhood obesity. The consumption of simple carbohydrates by all age groups in the United States has dramatically increased. These foods are high on the glycemic index and include breads, cereals, potatoes, cakes, refined sugar, sodas, etc. They promote high blood glucose levels and encourage over-eating in adolescents which leads to an increase in central adiposity.[2] Portion size also continues to increase and contributes to excessive food ingestion and increasing body mass. "Fast food" in particular incorporates many of the variables mentioned above and is typically high in saturated and trans fat, simple carbohydrates, and calories and is large in portion size. Its popularity continues to grow as family life becomes busier, and parents have less time to prepare conventional meals.

Social factors also play a role in the physical stature of children. Children who are neglected or who suffer from depression are more likely to become obese than their mentally healthy counterparts.[2]. Studies demonstrate that children with obese parents are more likely to become obese themselves. In fact, children born to two obese parents 
have a $70 \%$ chance of becoming obese. Those with one obese parent have a $50 \%$ chance of becoming obese, while children born to two normal weighted parents have only a $10 \%$ likelihood. Further, children of lower socioeconomic status who are part of single parent families, and who have uneducated parents are also at increased risk.[3] The weighted importance and interaction of each factor, however, is still yet to be determined and further research is necessary. Of course, each child is unique and affected differently by each variable, but a better understanding of the impact of the risk factors on a child's stature is important to prevent obesity and its associated problems.

Many ramifications and negative medical consequences are associated with childhood obesity. These include high blood pressure, increased incidence of Type II diabetes, increased total cholesterol, polycystic ovary syndrome, hepatic steatosis, gallstone formation, accelerated growth, Blount's disease, low self esteem, asthma, sleep apnea and increased risk for obesity in adulthood.[4]

Hypertension is a serious consequence of childhood obesity. It may present as dizziness, heart palpitations, easy fatigability, epistaxis, hematuria, blurred vision, angina pectoris, loss of breath or as an aneurism. If the onset of hypertension occurs during childhood and is prolonged, it can cause cerebrovascular insufficiency, congestive heart failure, peripheral vascular insufficiency and premature death.[5]

The incidence of Type II diabetes is greatly increased in obese children. In a survey conducted by The National Health and Nutrition Examination Survey, $85 \%$ of children diagnosed with Type II diabetes were either overweight or obese. In a recent study of obese children, $25 \%$ of the $4-10$ year olds and $21 \%$ of adolescents were diagnosed with impaired oral glucose tolerance. The complications associated with this 
can slowly destroy critical functions of the body. Most symptoms appear 15-20 years after the initial diagnosis of hyperglycemia. Atherosclerosis is one such complication and is caused by an accumulation of plaque within the arteries and an increased platelet adhesiveness, both of which tend to narrow the lumen of the arteries. Diabetic retinopathy is a leading cause of blindness in the United States. Neuropathy, another complication, presents as numbness, paresthesia, or pain and can affect muscular units resulting in an abnormality of gait and even as a fracture of the tarsal bones. The vascular disease associated with diabetes often causes a diminished blood supply that results in ulcers and an increased risk of infection. [5] Finally, obese children often have an increase in total cholesterol which may increase blood pressure and eventually lead to angina pectoris, myocardial infarction or congestive heart failure.

Excessive adipose tissue results in excessive androgen production in lieu of estrogen, contributing to the development of polycystic ovary syndrome. This syndrome is characterized by unpredictable uterine bleeding that varies in timing and amount. The increased amount of androgen produced perpetuates the chronic anovulation by causing a deficiency of Follicle Stimulating Hormone (FSH) and an excess of Lutenizing Hormone (LH). Therefore, the increased amount of adipose tissue rather than an intrinsic problem with the ovaries causes the infertility.[5]

Gallstones are prevalent in the United States and are also a side effect of obesity. Autopsies indicate that $20 \%$ of women and $8 \%$ of men over the age of 40 are affected.[5] Obesity causes the secretion of cholesterol which is required for the formation of gall stones. They typically cause inflammation or obstruction of the cystic duct which increases intralumenary pressure and causes severe pain or a steady ache in the abdomen. 
In Blount's disease, the tibia fails to develop normally in obese patients because of the excessive weight it bears. A medial angulation of the tibia in the area of the proximal epiphyseal plate leads to a bowing of the legs in the area of the knees. Each leg responds slightly differently; therefore differences in leg length are common. The condition also results in the medial rotation of the tibia further leading to an inward rotation of the foot. The disease is not self limiting and will likely worsen unless corrective action is taken. Depending on the severity of the disease and the age of the patient, treatment may include leg braces or surgery.[6]

Clinical studies have shown that obese children experience psychological problems and feelings of low self-esteem more often than children of normal body mass. This condition occurs more often in females than males and worsens with age. One study concluded that $34 \%$ of obese white females between the ages of $13-14$ have low self esteem, while only $8 \%$ of nonobese white females in the same age group are affected.[7] Obese children often receive excessive teasing throughout their lives, especially during their teenage years which tends to be the most damaging and frequently results in feelings of low self esteem. This condition represents a serious social impairment for these children, and teachers often perceive them less favorably than children of normal weight. If the condition continues into adulthood lasting consequences can occur. In a National longitudinal survey of 10,000 females age 16-24 years, the obese females were less likely to complete college or to marry and were more likely to face employment discrimination, to earn less money, to have less formal schooling and to have less material wealth than their nonobese counterparts.[4] 
Obesity is one of the major causes leading to an accumulation of tryglycerides in the hepatocytes, commonly known as hepatic steatosis, or fatty liver. This condition usually results in only minor discomfort, slight elevations of alkaline phosphatase, and a minor enlargement of the liver. More significant consequences such as jaundice and prolonged blood clotting times can occur however, which may indicate fibrosis or cirrosis of the liver.[5]

Obesity increases the risk for developing asthma, which is characterized by a narrowing of the air passages. Over-responsiveness of the trachea and bronchioles to external stimuli cause such narrowing and presents clinically as coughing, wheezing and general difficulty in breathing. Asthma is an episodic disease with acute attacks lasting from minutes to hours often followed by what appears to be a full recovery. The duration between attacks varies, and it is difficult to predict what will precipitate the next attack or when it will occur. In some instances, the narrowing of the tracheobronchial tree can become so severe that the patient cannot adequately perfuse the blood with oxygen. In some extreme cases, the disease requires hospitalization and could lead to death.[5]

Obesity is often associated with Obstructive Sleep Apnea (OSA) which is fairly common but still represents a potentially life threatening problem. Classic symptoms include loud snoring during sleep and excessive sleepiness during the day. Nearly all people inflicted with the disorder are symptomatic.[8] During sleep, the upper airway becomes obstructed which temporarily causes patients to stop breathing. The concentration of carbon dioxide in the blood rises until the patient awakens and begins breathing again. The respiration saturates the blood with oxygen, the patient falls back to sleep, and the cycle continues. This not only leads to a restless nights sleep, but creates a 
dangerous situation in which the patient could suffocate.[8] Although certain types of craniofacial characteristics have been identified as contributing factors to the onset of sleep apnea, the complete cause of the condition is not yet fully known.

The upper airway is the only part of the airway that is not surrounded by hard cartilaginous rings to define its shape. Within the upper airway, a large tongue is a risk factor for developing OSA. Xiujun Yu et al., (2002) found that large tongues were common in sleep apnea patients. When in the supine position, large tongues fall posteriorly obstructing the hypopharyngeal space and occluding the airway. An excessively long soft palate is also a risk factor and may constrict the upper pharyngeal air space when the patient is in the supine position. A deficient mandible and an inferiorly positioned hyoid bone also appear to contribute. The position of the hyoid bone is significant, because it anchors the tongue muscles. When it is inferiorly positioned, the tongue is allowed to drop back and down.[8] Evidence suggests that excessive adipose tissue and an increased BMI significantly increase the risk for OSA. Excessive deposition of adipose tissue in the upper airways of obese patients greatly increases their risk for acquiring this syndrome.[8]

Recent studies indicate that obesity may impact the size and shape of the craniofacial skeleton and directly influence the potential for sleep apnea. In 2001, Paoli et al., conducted a study to determine if certain craniofacial malformations contributed to the occurrence of OSA. He hypothesized that particular malformations increased a subject's risk of developing OSA regardless of the afflicted individual's body mass composition. To help identify these malformations, he evaluated cranial base length using Sella to Nasion ( $\mathrm{S}-\mathrm{N}$ ), the anterior-posterior relationship of the maxilla to the 
mandible, the Sella to Nasion to A-point angle (SNA), the Sella to Nasion to B-point angle (SNB) and the A-point to Nasion to B-point angle (ANB). The size of the mandible and maxilla were also evaluated using Posterior Nasal Spine (PNS) to A-point and the Gonion to Menton (Go-Me) measurements, respectively. Two groups, obese and normal weight, were evaluated with the slightly obese patients included within the normal weight group. When the results were examined, the obese group had significantly longer cranial bases, significantly smaller ANB angles and significantly longer mandibles which were positioned more anteriorly than the "normal" group.[9]

In March 2003, Ferrario et al., attempted to establish a correlation between craniofacial measurements and BMI using anthropometric measurements. They evaluated 25 subjects using a three dimensional coordinate system and 12 facial soft tissue landmarks. They defined obesity as a BMI of 30 or higher and grouped patients as severely obese, obese, slightly obese, and normal. In this cross sectional study, all facial measurements were analyzed in three dimensions. They concluded that obese adolescents had wider skull bases and mandibles, deeper mid and lower faces, longer mandibles, and shorter upper facial heights than their non-obese counterparts. Unlike the study conducted by Paoli, Ferrario found the slightly obese group had statistically significant differences from the norm, with some having facial characteristics more similar to the severely obese group.[10]

In Sweden, Ohrn et al., theorized that some of the hard tissue components of the head would be reduced in size in obese patients, because they have lower rates of growth hormone production. She performed a cross sectional study of 25 female and 14 male adolescent patients and made various linear and angular measurements using standard 
lateral cephalometric tracings. The linear measurements evaluated included cranial base length, anterior total face height, upper anterior face height, lower anterior face height, sella to gonion, hard palate length, condylion to pogonion, and mandibular body length. The angular measurements included SNA, SNB, SNPg, NSBa, palatal plane to S-N, and mandibular plane angle.[11] The results indicated that obese adolescents had increased linear and angular measurements, with differences occurring more frequently in females than in males. The length of the mandible had the largest discrepancy between obese and non-obese subjects. Both jaws and the anterior cranial base in obese patients exhibited increased length. Aside from the measurements of prognathism, there were no significant angular measurement differences between the male groups. In the female groups, the obese patients exhibited significantly lower mandibular plane angles. The authors concluded that the obese children demonstrated more growth before the pubertal growth spurt than did the non-obese children.[11] In comparison to lean children, obese children are often taller prior to puberty but closer in height after puberty. Therefore, the authors speculated that the pubertal growth spurt is less drastic, but longer with a more gradual curve in obese children than in lean children. This implies that there is no difference between the final craniofacial dimensions between obese and lean adolescents.[11]

Unfortunately, the research currently available regarding craniofacial growth and obesity is incomplete. The sample sizes used were small (i.e. 85 or less), and no one has evaluated both hard and soft tissues. Further, no longitudinal studies exist to determine if craniofacial dimensions in obese patients continue to be larger than their non-obese counterparts after the pubertal growth spurt. Currently, most research on the subject of obesity and craniofacial dimensions rclates to sleep apnea. Thus, many of the 
craniofacial measurements that are of interest to the orthodontic community have not been addressed by any of the previous studies. Therefore, the purposes of this study are to confirm the accuracy of the previously published results and to determine if obesity is related to altered orthodontic craniofacial measurements. Specifically our aims were: 1) to test the results that have already been published stating that obese children have certain craniofacial structures that are significantly larger than their lean counterparts, 2) to evaluate orthodontically related hard and soft tissue measurements to determine if obesity has an effect on growth, 3) to determine if a difference exists between male and female craniofacial structures, 4) to determine if there is a difference between the craniofacial structures of overweight patients and obese patients and 5) to determine if a difference in craniofacial structure exists between various age groups.

More specifically we hypothesized: 1) that the results and conclusions of previous studies were accurate, 2) obesity does significantly affect various components of the craniofacial complex (i.e. more prognathic maxillas and mandibles), 3) male and female craniofacial structures differ significantly in size, 4) the craniofacial structures of obese patients are affected more than simply overweight patients, and 5) there are significant differences in craniofacial structures between the varying age groups. 


\section{METHODS AND MATERIALS}

Appropriate Institutional Review Board (IRB) approval was obtained at the University of Louisville in November 2003 (reference number 569.03.) The study comprised a chart review of patients at the University of Louisville Graduate Orthodontic Clinic. During the orthodontic records appointment, all new patients routinely receive lateral cephalometric radiographs as well as height and weight measurements. Both the lateral cephalometric radiograph and the height-weight measurements were used in this study to establish craniofacial dimensions and BMI. Inclusion criteria required that the patients be either Caucasian or African American, under 19 years of age, and healthy (no endocrine or developmental disorders). All new patients who satisfied the inclusion criteria between January 2003 and September 2004 were accepted into the study as subjects.

The radiographs were taken by one of three different dental assistants using the Instrumentarium Orthopantomograph OP 100/Orthoceph OC 100. All patients were given the same set of instructions. They were asked to remove any jewelry involving their head and neck, to stand up straight, and to remain motionless while occluding (maximum intercuspation) on their posterior teeth. Ear rods were placed into the ears, the Franfort Horizontal Plane (FH) was parallel to the floor, and the midsagital plane was perpendicular to the floor. The nasion rest was placed in contact with the deepest part of 
the bridge of the nose. The radiograph machine was set at $77 \mathrm{kVp}, 12 \mathrm{~mA}$, and either $0.4 \mathrm{~s}$ or $0.5 \mathrm{~s}$ depending on the size of the patient. Nexadental $8 \times 12$ radiographic film was used and processed by the All-Pro Imaging 100 Plus Automatic X-ray film processor. Processing chemicals were monitored every 7 days by the same representative of Commonwealth X-ray Company and replenished or changed when necessary.

All lateral cephalometric radiographs used rare earth screens in order to lower the radiation dose to the patient while maintaining diagnostic quality. The patients were positioned five feet (standard) from the radiation source, and the magnification ( 8 and 14 percent) was dependant on the distance from the radiographic film to the patient's head. The film cassette was positioned as close to the patient's head as possible without contacting their shoulders. Height measurements were made with patients standing with their backs against the wall where a tape measure was fixed. A pencil was placed on top of the head marking the corresponding height to the nearest 0.1 inches. All weight measurements were made using one digital scale which was calibrated to within one pound. At the completion of the measurements, one of the three dental assistants who had been calibrated, recorded the date, the height, and the weight.

Body Mass Index (BMI) was calculated by dividing the body weight in kilograms by the square of the body height in meters, or [Weight $(\mathrm{kg}) /(\operatorname{Height}(\mathrm{M}) \mathrm{X} \operatorname{Height}(\mathrm{M}))]$. Patients whose BMI was 25 or less were considered "normal weight, while those with a BMI of 26 to 30 were considered "over-weight", and those whose BMI was above 30 were considered "obese".[12]

Twenty-one planes and angles were evaluated in the study and recorded for comparison. All the associated points are illustrated in Figure 1. 


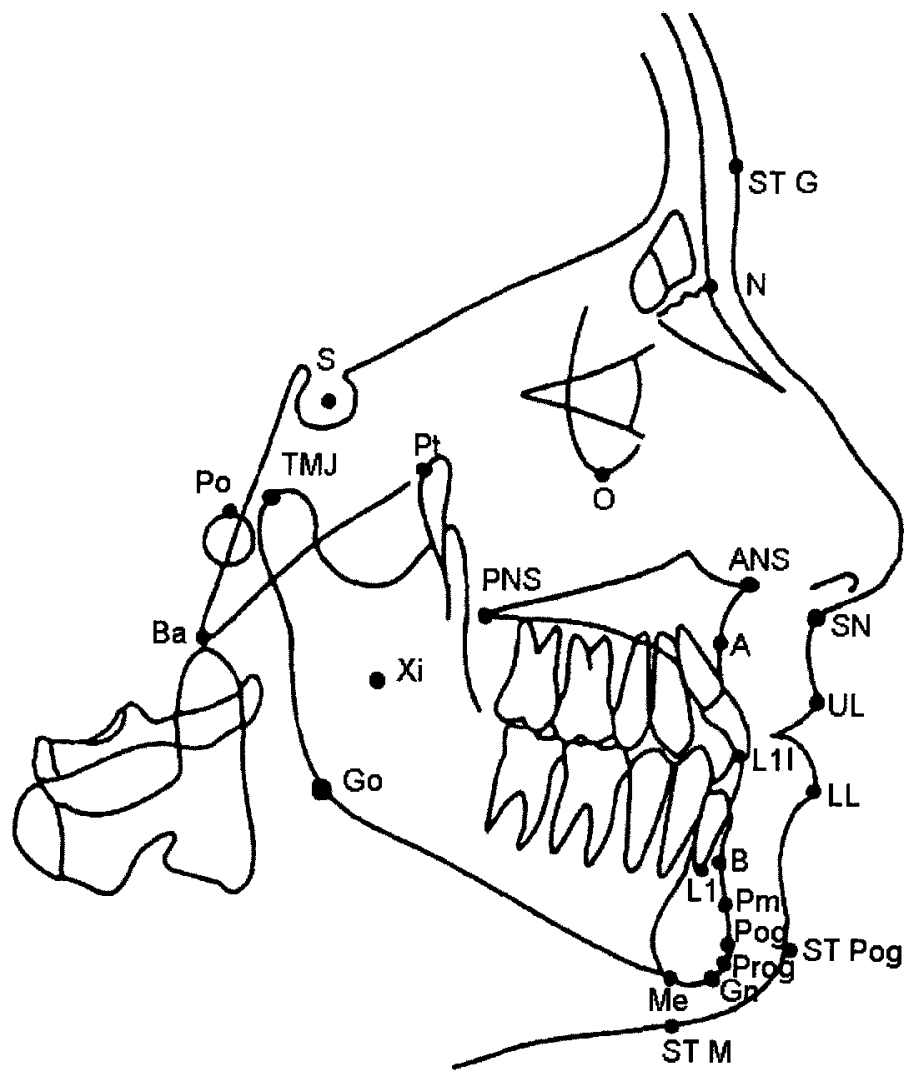

A - A point

ANS - Anterior Nasal spine

$B-B$ point

Ba - Basion

Go - Gonion

Gn - Gnathion

L1 - Lower incisor root apex

LL - Lower Lip

L1I - Lower Incisor tip

Me - Menton

N- Nasion

O- Orbitale

Pm - Protuberance menti

PNS - Posterior Nasal Spine

Po - Porion

Pog - pogonion

Pt - Pt point

Prog - Prognathion

S - Sella

SN - Subnasale

ST G - Soft Tissue Glabella

ST M - Soft Tissue Menton

ST Pog - Soft Tissue Pogonion

TMJ - TMJ point

UL - Upper Lip

Xi - Xi point

Figure 1. Illustration of the anatomical points used in this study. 


\section{Table 1:}

\section{Description of all points listed in figure 1.}

\begin{tabular}{|c|c|c|c|}
\hline $\begin{array}{l}\text { Anatomical } \\
\text { Point }\end{array}$ & Description & $\begin{array}{l}\text { Anatomical } \\
\text { Point }\end{array}$ & Description \\
\hline $\bar{A}$ & $\begin{array}{l}\text { The junction of the maxillary } \\
\text { basal bone with the alveolar } \\
\text { bone }\end{array}$ & PNS & $\begin{array}{l}\text { The most posterior point on the } \\
\text { spine of the palantine bone }\end{array}$ \\
\hline ANS & $\begin{array}{l}\text { The tip of the spinous process } \\
\text { of the maxilla }\end{array}$ & Po & $\begin{array}{l}\text { The midpoint of the upper contour } \\
\text { of the external auditory meatus }\end{array}$ \\
\hline B & $\begin{array}{l}\text { The junction of the mandibular } \\
\text { basal bone with the alveolar } \\
\text { bone }\end{array}$ & Pog & $\begin{array}{l}\text { The most anterior point of the } \\
\text { bony chin }\end{array}$ \\
\hline $\mathrm{Ba}$ & $\begin{array}{l}\text { The lowest point on the } \\
\text { anterior margin of the foramen } \\
\text { magnum }\end{array}$ & $\mathrm{Pt}$ & $\begin{array}{l}\text { The posterior superior border of } \\
\text { the pterygopalatine fossa }\end{array}$ \\
\hline Go & $\begin{array}{l}\text { The most outward point on the } \\
\text { angle of the mandible }\end{array}$ & Prog & $\begin{array}{l}\text { The point on the contour of the } \\
\text { bony chin }\end{array}$ \\
\hline Gn & $\begin{array}{l}\text { The most anterior inferior point } \\
\text { on the bony chin }\end{array}$ & $\mathrm{S}$ & The center of the pituitary cavity \\
\hline $\mathrm{Ll}$ & Lower central incisor root apex & $\mathrm{SN}$ & $\begin{array}{l}\text { Where the nose connects to the } \\
\text { middle of the upper lip }\end{array}$ \\
\hline LL & $\begin{array}{l}\text { The most anterior point on the } \\
\text { curve of the lower lip }\end{array}$ & ST G & $\begin{array}{l}\text { Most anterior point on the soft } \\
\text { tissue covering the frontal bone }\end{array}$ \\
\hline L1I & $\begin{array}{l}\text { Lower central incisor incisal } \\
\text { edge }\end{array}$ & ST M & $\begin{array}{l}\text { The most inferior point on the soft } \\
\text { tissue chin }\end{array}$ \\
\hline $\mathrm{Me}$ & $\begin{array}{l}\text { The most inferior point on the } \\
\text { mandibular symphysis }\end{array}$ & ST Pog & $\begin{array}{l}\text { The point on the curve of the soft } \\
\text { tissue chin }\end{array}$ \\
\hline $\mathrm{N}$ & $\begin{array}{l}\text { The most anterior point of the } \\
\text { junction of the frontal and nasal } \\
\text { bones }\end{array}$ & TMJ & Posterior wall of the glenoid fossa \\
\hline $\mathrm{O}$ & $\begin{array}{l}\text { The lowest point on the inferior } \\
\text { border of the bony orbits }\end{array}$ & UL & $\begin{array}{l}\text { Most anterior point on the curve of } \\
\text { the upper lip }\end{array}$ \\
\hline $\mathrm{Pm}$ & $\begin{array}{l}\text { The point where the curvature } \\
\text { of the anterior border of the } \\
\text { mandibular symphysis changes }\end{array}$ & $\mathrm{Xi}$ & $\begin{array}{l}\text { A constructed point that represents } \\
\text { the geometric center of the } \\
\text { mandibular ramus }\end{array}$ \\
\hline
\end{tabular}




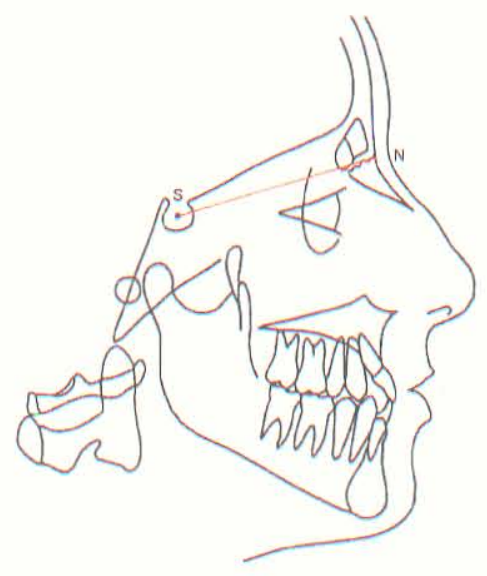

Figure 2. The Anterior Cranial Base length (S-N) - This line is formed by connecting sella to nasion. It is one of the two major reference planes associated with the cranium.

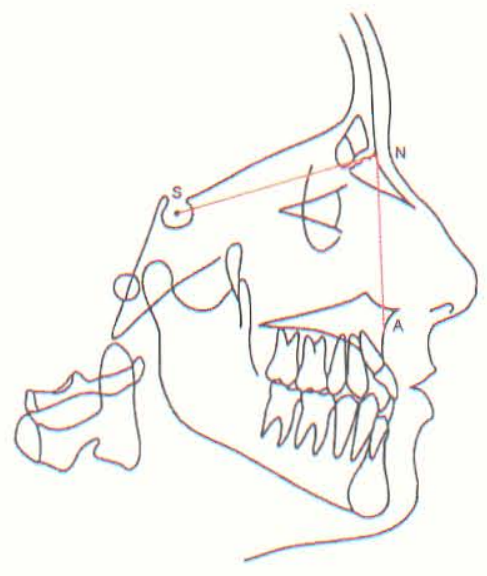

Figure 3. Sella Nasion A point (SNA) - The SNA angle measures the anterior posterior position of the maxilla in relation to the cranial base. It is the angle formed by the intersection of the S-N and N-A lines. 


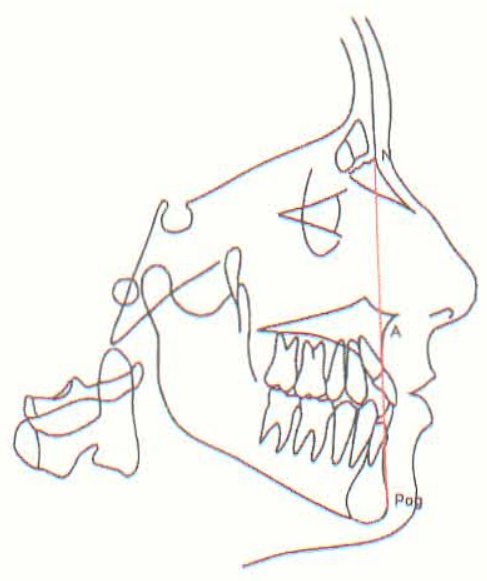

Figure 4. A-point Convexity - This references the anterior posterior position of the maxilla. It is found by measuring the distance from A-point to the line connecting nasion to pogonion, (facial plane).

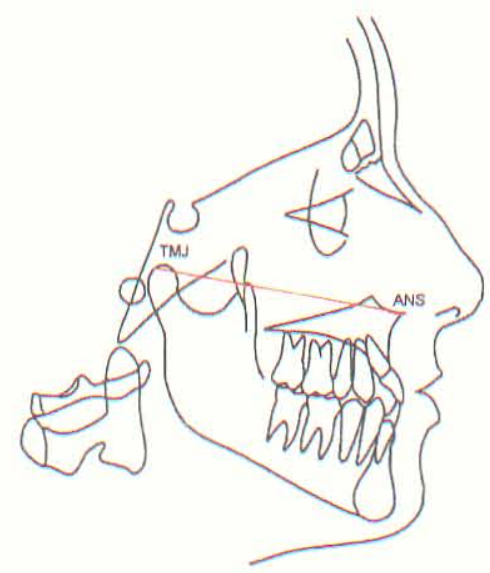

Figure 5. Maxillary Unit Length - This is the linear measurement from TMJ-point to Anterior Nasal Spine. This measurement estimates the length of the maxilla in the sagittal plane. 


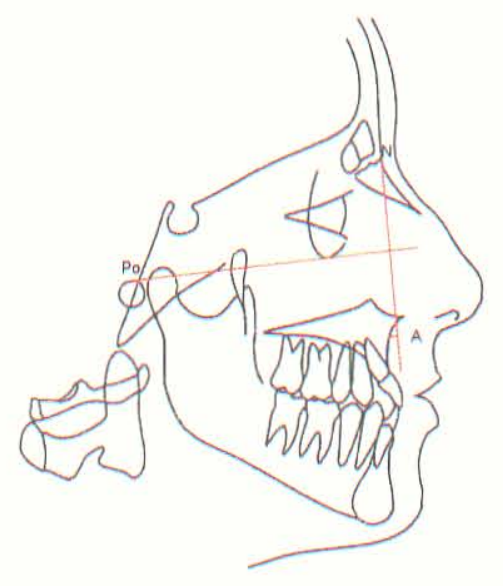

Figure 6. A-point to N-point perpendicular (A to N perp.) - This linear measurement is found by constructing a perpendicular line to the Frankfort Horizontal (FH) passing through $\mathrm{N}$-point and measuring the distance from that line to A pt. It indicates the protrusion of the maxilla relative to nasion.

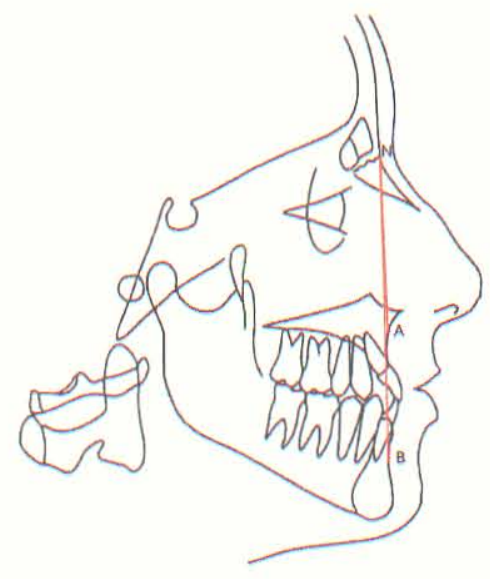

Figure 7. A-point N-point B-point (ANB) - This angle relates the sagittal position of the maxilla to the mandible. It is formed by the intersection of the lines N-A and N-B. The larger this angle is, the more anteriorly positioned the maxilla is in relation to the mandible. 


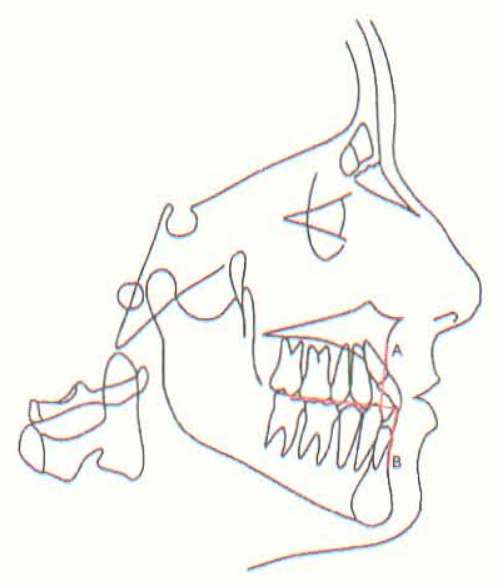

Figure 8. Wits - This measures the relationship of the maxilla to the mandible. It is calculated by drawing perpendicular lines from A-point and B-point to intersect the functional occlusal plane. The distance is measured between the two intersecting points.

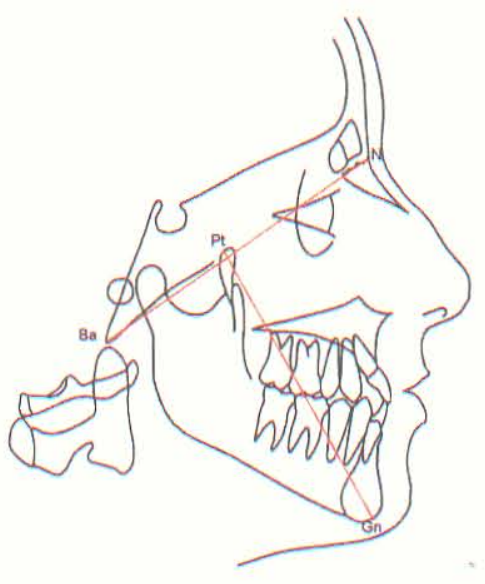

Figure 9. Facial Axis - This angle is calculated by measuring the inferior angle formed by the intersection of the N-Basion (Ba) line and the Pt point $(\mathrm{Pt})$-Gnathion $(\mathrm{Gn})$ line. A small angle indicates that the patient's mandible is growing in a predominantly vertical direction, and a large angle indicates that the patient's mandible is growing in a predominantly horizontal direction. 


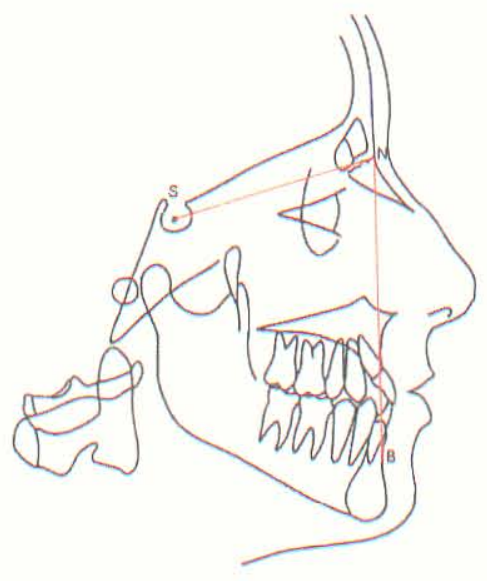

Figure 10. S-point N-point B-point (SNB) - This measurement is used to establish the relationship of the anterior mandible to the cranial base and indicates mandibular protrusion. It is determined by measuring the angle between the $\mathrm{S}-\mathrm{N}$ and the $\mathrm{N}-\mathrm{B}$ lines.

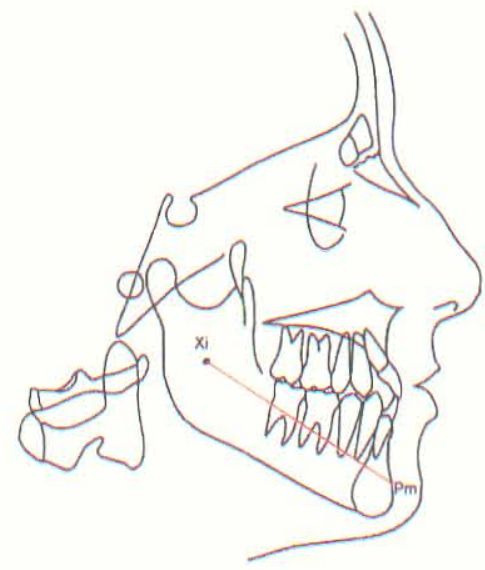

Figure 11. Corpus Length - This measurement describes the length of the mandible from the midpoint of the ramus, Xi point, to protuberance menti. It describes the length of the body of the mandible and indicates the degree of mandibular prognathism. 


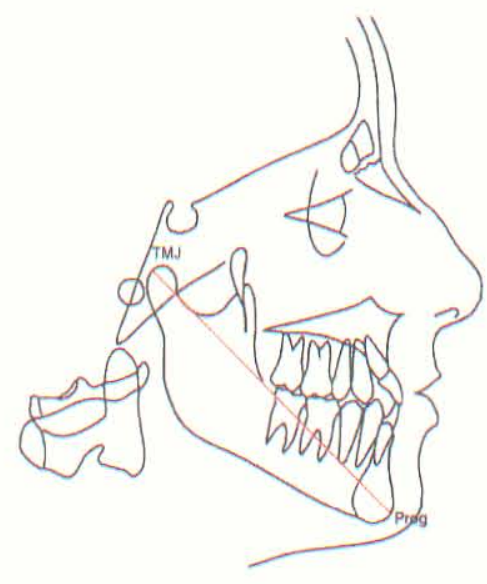

Figure 12. Mandibular Unit Length - This measures the length of the entire mandible in the anterior-posterior direction. The end points of the linear measurement are TMJ point posteriorly and prognathion anteriorly. These anatomic locations describe the most posterior superior and anterior inferior points of the mandible respectively, and thus measures its entire length.

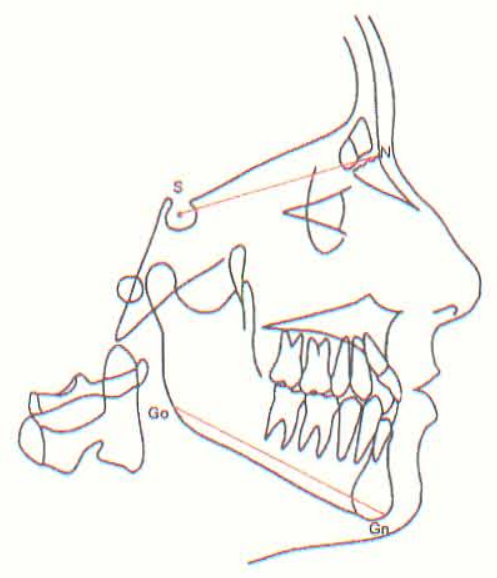

Figure 13. Sella-Nasion to Gonion-Gnathion (S-N to Go-Gn) - This measurement is used to determine the inclination of the mandibular plane relative to the cranial base. It is found by measuring the anterior angle between the planes formed by the cranial base and the inferior border of the mandible. 


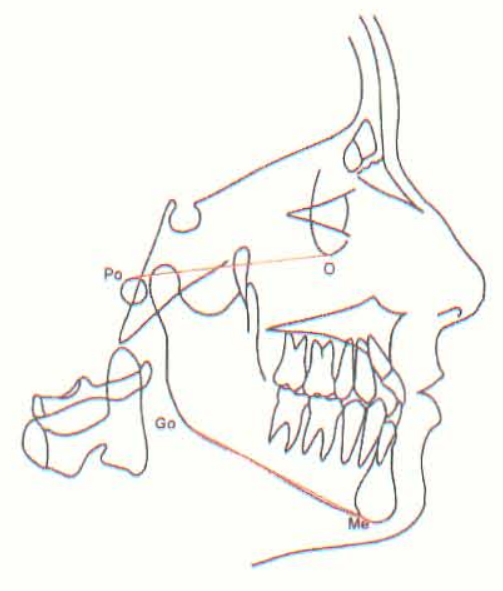

Figure 14. Frankfort Mandibular Plane Angle (FMA) - The mandibular plane angle completes the Tweed triangle by measuring the anterior angle between FH and the line connecting gonion (Go) and menton (Me). It is similar to the S-N to Go-Gn measurement as it measures mandibular inclination.

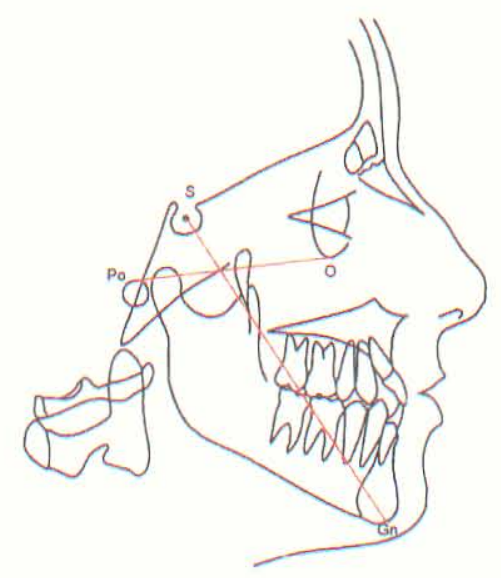

Figure 15. Y-axis - This angular measurement is designed to evaluate the vertical growth pattern of the mandible. It is found by measuring the anterior inferior angle between the S-Gn line and FH. 


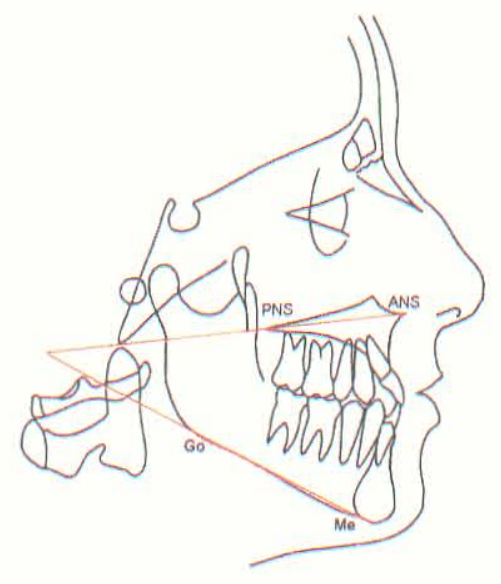

Figure 16. Mandibular Plane to Palatal Plane (MP-PP) - The mandibular plane is defined by the line connecting Me to Go, and the palatal plane is defined by the line connecting Anterior Nasal Spine (ANS) to Posterior Nasal Spine (PNS). The anterior angle made by the intersection of these two lines is the angle of interest and indicates the mandibular vertical growth pattern.

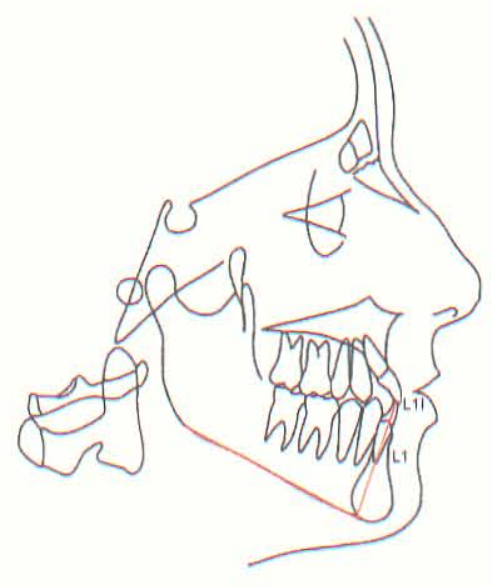

Figure 17. IMPA - This measurement relates the inclination of the lower incisor to the lower border of the mandible. It measures the posterior angle between the long axis of the lower incisor and a tangent to the inferior border of the mandible. 


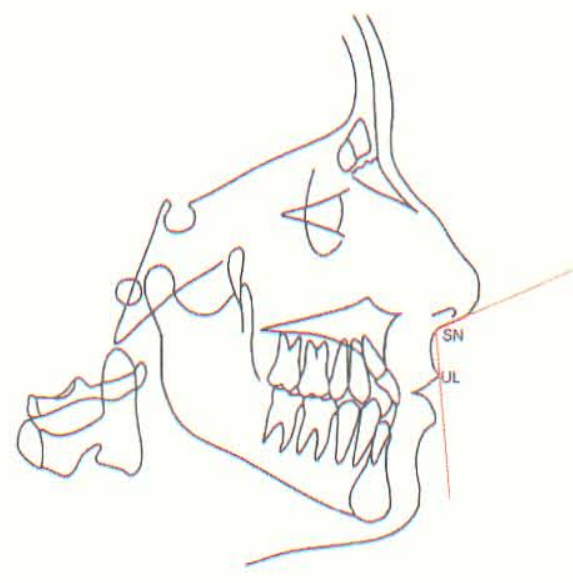

Figure 18. Nasolabial Angle - This angle is formed by a line tangent to columella of the nose and a line connecting subnasale (SN) to the soft tissue border of the upper lip (UL). This angle measures protrusion of the upper lip and the maxillary anterior dentition.

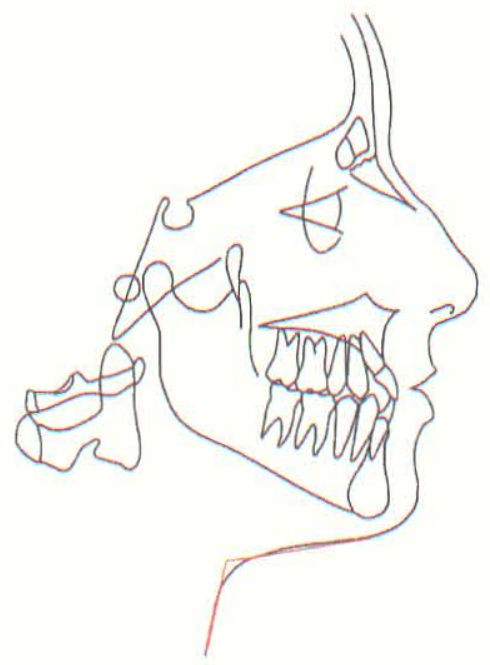

Figure 19. Chin Throat Angle - This measures the angle of the neck with the submandibular soft tissue. This measurement indicates the length of the mandible and the amount of adipose tissue. The angle is made by the intersection of the lines tangent to the neck and to the submandibular soft tissue. 


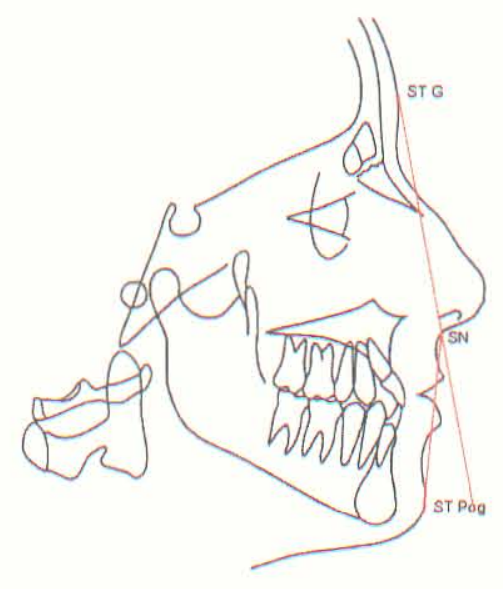

Figure 20. Soft Tissue Convexity - The convexity is found by measuring the inferior angle formed by the intersections of the Soft Tissue Glabella (ST G), subnasale (SN) line and the SN, Soft Tissue Pogonion (ST Pog) line. This measurement indicates the relative position of the mandible in the AP plane with respect to the upper facial profile.

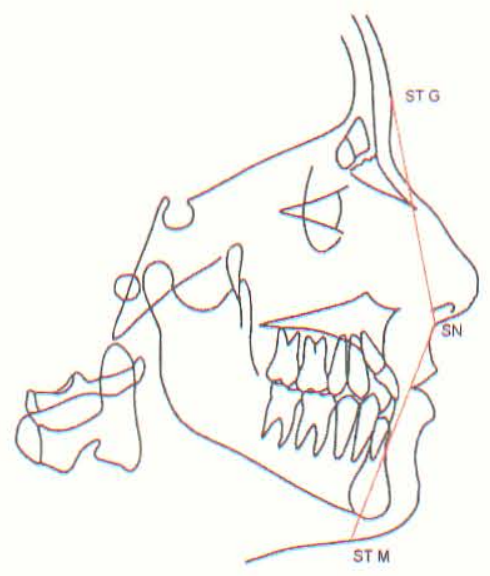

Figure 21. Soft Tissue Facial Height Ratio - Gives the ratio between the vertical height of the upper face and the vertical height of the lower face. It is calculated by dividing the distance from ST G to SN by the distance from SN to ST M. 


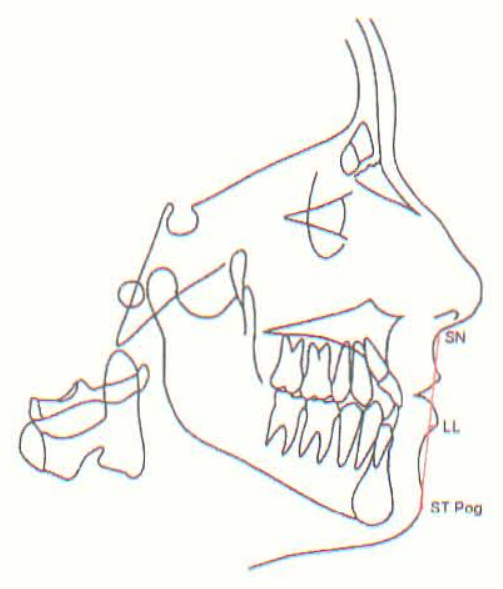

Figure 22. Lower Lip to E-Plane - Measures the protrusion of the lower lip. The length is found by measuring the distance from the most anterior point on the lower lip (LL) to the plane defined by SN-ST Pog.

All the lateral cephalometric radiographs were hand traced onto acetate tracing paper by one investigator to minimize interobserver variability. Five randomly selected radiographs were retraced and compared to the original tracings to verify that the intraobserver variability was within acceptable limits. Correlations between the two tracings of each of the five radiographs were compared, and ranged from 0.995 to 0.999 indicating a high level of consistency. Since only one investigator performed the tracings, no interobserver variability existed. After the radiographs were traced, they were digitized, entered into the computer, and analyzed using Dental Facial Planner.

BMI was calculated for each subject who were then categorized into one of three groups. Those subjects with a BMI of less than 25 were placed in the "normal weight" category, those whose BMI was between 25 and 30 were placed in the "overweight" category and those whose BMI was over 30 were placed in the "obese" group. The various craniofacial measurements were then compared using Analysis of Variance, 
(ANOVA) with BMI as the independant variable. Second, the craniofacial measurements were compared using ANOVA with gender as the independant variable.

Finally, patients were placed into categories to estimate pre-pubertal, pubertal and postpubertal groupings as follows:

1) $4-10.9$ years

2) 11-12.9 years

3) 13-14.9 years

4) $15-19.9$ years

The craniofacial measurements of the four age groups were then compared using ANOVA.

The data collected from this study was analyzed using the Statistical Package for Social Sciences (SPSS 12.0) software to determine if there was a significant difference between the craniofacial measurements with BMI, age and gender as the independent variables. Thus, three ANOVAs were computed. If the omnibus F test showed a statistically significant difference for BMI or age, Tukey's post hoc procedure was used to compute pairwise comparisons. Since gender has only two categories, post hoc analysis was not appropriate and was not performed. 


\section{RESULTS}

The data for this project was collected over a six month period and a total of 150 subjects were included.

\section{Table 2:}

Number of Patients Exhibiting Each of the Independent Variables Evaluated

\begin{tabular}{ll}
\hline Independent variable & No. of Subjects \\
\hline$\underline{\text { BMI }}$ Less than 25 & 111 \\
$25-30$ & 19 \\
More than 30 & 20 \\
Gender & \\
Male & 61 \\
Female & 89 \\
Age & \\
$4-10.9$ & 30 \\
$11-12.9$ & 48 \\
$13-14.9$ & 51 \\
$15-20$ & 21 \\
\end{tabular}

Table 2 describes the patient demographics of those subjects included in our study. It lists the number of patients that fell into each of the categories evaluated. 


\section{Table3:}

Mean, Norm and Standard Deviation Values for Selected Craniofacial Dimensions

\begin{tabular}{llll}
\hline Craniofacial Measurement & Study Value & Norm & Norm S.D. \\
& & & \\
\hline Ant Cranial Lth (mm) & 59.1 & 55.0 & 2.5 \\
SNA (deg) & 82.9 & 81.4 & 3.3 \\
A pt Convexity (mm) & 3.2 & 1.0 & 2.0 \\
Mx unit Lth (mm) & 96.3 & 92.0 & 4.5 \\
A pt to N perp (mm) & 1.3 & 0.4 & 2.7 \\
ANB (deg) & 3.9 & 3.7 & 2.1 \\
Wits (mm) & 0.6 & -0.4 & 2.0 \\
Facial Axis (deg) & 88.8 & 90 & 3.5 \\
IMPA (deg) & 89.1 & 90 & 10 \\
SNB (deg) & 79.2 & 77.7 & 2.7 \\
Corpus Length (mm) & 73.4 & 73.0 & 2.7 \\
Mand Unit Length (mm) & 122.4 & 117.0 & 6.1 \\
SN to GoGn (deg) & 32.4 & 34.0 & 4.8 \\
Mand Plane (deg) & 24.6 & 24.3 & 4.5 \\
Y Axis (deg) & 57.9 & 59.4 & 3.8 \\
MP - PP (deg) & 28.2 & 28.0 & 2.0 \\
Nasolabial Angle (deg) & 108.1 & 102.0 & 8.0 \\
Chin Throat Angle (deg) & 70.0 & 100.0 & 7.0 \\
S.T. Convexity (deg) & 14.3 & 12.0 & 4.0 \\
S.T. Facial Ht Ratio (\%) & 93.4 & 102.0 & 7.0 \\
Lower Lip to E-Plane (mm) & 0.3 & -3.0 & 2.0 \\
\hline
\end{tabular}

Table 3 describes the sample means of the selected craniofacial measurements, the norms and standard deviations as described by Schuler.[13] 


\section{Table 4:}

Variables Affecting Mean Craniofacial Measurements for Varying BMI's

\begin{tabular}{|c|c|c|c|c|c|c|c|c|}
\hline Body Mass Index & 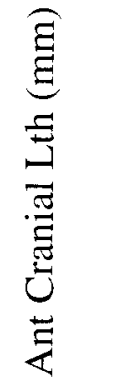 & 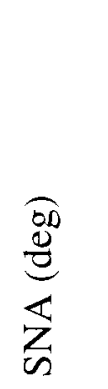 & 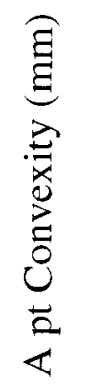 & 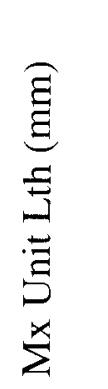 & 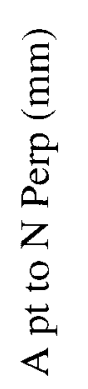 & $\begin{array}{l}\overparen{B D} \\
\stackrel{d}{0} \\
\frac{\infty}{Z} \\
z\end{array}$ & 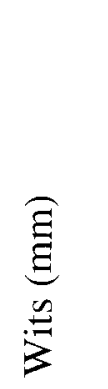 & 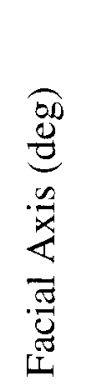 \\
\hline \multicolumn{9}{|l|}{ Normal Weight } \\
\hline Sample Size & 111 & 111 & 111 & 111 & 111 & 111 & 111 & 111 \\
\hline Mean & 58.93 & 81.98 & 3.05 & 95.51 & 1.60 & 3.73 & 0.91 & 88.5 \\
\hline $\begin{array}{l}\text { Std. Dev. } \\
\text { Over Weight }\end{array}$ & 4.61 & 4.80 & 3.53 & 6.07 & 5.71 & 3.08 & 4.12 & 4.64 \\
\hline Sample Size & 19 & 19 & 19 & 19 & 19 & 19 & 19 & 19 \\
\hline Mean & 58.58 & 86.11 & 3.88 & 97.57 & 1.03 & 4.23 & 0.56 & 89.6 \\
\hline $\begin{array}{l}\text { Std. Dev. } \\
\text { Obese }\end{array}$ & 3.07 & 5.65 & 3.12 & 51.16 & 4.95 & 2.71 & 4.03 & 3.70 \\
\hline$\overline{\text { Sample Size }}$ & 20 & 20 & 20 & 20 & 20 & 20 & 20 & 20 \\
\hline Mean & 60.59 & 84.76 & 3.26 & 99.77 & 0.10 & 3.31 & -0.67 & 90.1 \\
\hline Std. Dev. & 4.75 & 5.74 & 3.52 & 4.83 & 4.94 & 3.18 & 4.40 & 5.33 \\
\hline
\end{tabular}

All the measurements in table 4 are related to the anterior cranium or the maxilla.

Some of the measurements such as Anterior Cranial Length and Maxillary Unit Length are strictly linear measurements while the other measurements, SNA, A pt Convexity, A pt to N Perp., ANB and Facial Axis all describe the relative protrusion of the maxilla in relation to other craniofacial structures.

We found two measurements in this group that showed significant statistical differences. The angle defined by the anatomical reference points SNA showed a significant difference when compared against patients in the different BMI groups. Those patients who fell into the overweight category have a statistically significant 
$(\mathrm{P}=0.004)$ larger measurement $(86.111)$ than those who fell into the normal weight category (81.983). The obese patients however were not found to have a significantly $(\mathrm{P}=0.072)$ larger SNA measurement $(84.760)$ than either the normal weight individuals or the overweight individuals.

Maxillary Unit Length, a strictly linear measurement of the maxilla, showed a statistically significant difference when compared against the different BMI groups. The obese individuals had a significantly $(\mathrm{P}=0.006)$ larger maxillary unit length (99.77) when compared against the normal weight (95.51), but there were no significant differences noted between the normal group and the overweight group (97.57) or between the over weight group and the obese group. Anterior cranial length, A-pt convexity, A-pt to N perpendicular, ANB and the Wits measurements showed no significant differences when compared using the BMI groupings. 
Table 5:

Variables Affecting Mean Craniofacial Measurements for Varying BMI's

\begin{tabular}{|c|c|c|c|c|c|c|c|}
\hline $\begin{array}{l}\text { Body Mass } \\
\text { Index }\end{array}$ & $\begin{array}{l}\widehat{O D} \\
\stackrel{d}{e} \\
\stackrel{n}{Z} \\
\tilde{n}\end{array}$ & 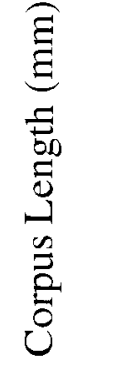 & 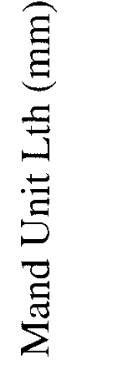 & 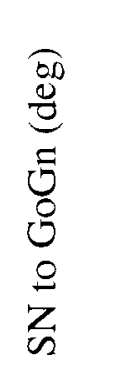 & 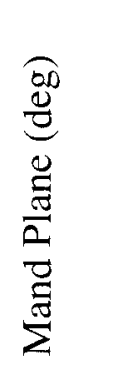 & 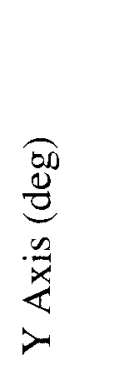 & 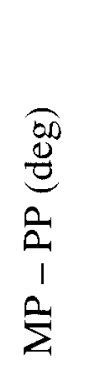 \\
\hline \multicolumn{8}{|l|}{ Normal } \\
\hline Sample Size & 111 & 111 & 111 & 111 & 111 & 111 & 111 \\
\hline Mean & 78.27 & 72.26 & 120.71 & 32.49 & 24.33 & 57.61 & 27.64 \\
\hline $\begin{array}{l}\text { Std. Dev } \\
\text { Over Weight }\end{array}$ & 4.33 & 5.08 & 7.55 & 6.10 & 5.85 & 4.25 & 5.46 \\
\hline Sample Size & 19 & 19 & 19 & 19 & 19 & 19 & 19 \\
\hline Mean & 81.47 & 75.43 & 124.51 & 30.99 & 24.54 & 58.50 & 29.23 \\
\hline $\begin{array}{l}\text { Std. Dev } \\
\text { Obese }\end{array}$ & 5.13 & 5.73 & 8.68 & 5.86 & 5.44 & 3.53 & 5.98 \\
\hline Sample Size & 20 & 20 & 20 & 20 & 20 & 20 & 20 \\
\hline Mean & 81.85 & 77.50 & 129.72 & 32.91 & 26.26 & 58.95 & 30.40 \\
\hline Std. Dev & 6.24 & 5.38 & 8.27 & 5.58 & 5.84 & 3.72 & 6.72 \\
\hline
\end{tabular}

The measurements in Table 5 are all related to the mandible. SNB relates the relative protrusion of the mandible to the maxilla. Corpus length and mandibular unit length are linear measurements describing the length of the mandible. S-N to GoGn, mandibular plane, Y-Axis and MP-PP are all indicators of the vertical growth pattern of the mandible.

The angle defined by the anatomical reference points SNB shows significant differences when compared among the specified BMI groups. Our findings show that as BMI increases, SNB also increases. Normal weight individuals have a mean 
measurement of (78.27) overweight individual have a mean measurement of (81.47) and obese individuals have a mean measurement of (81.85). There is a significant difference between normal weight individuals and overweight individuals $(\mathrm{P}=0.021)$ and between normal weight individuals and obese individuals $(\mathrm{P}=0.007)$ but not between overweight and obese individuals.

Significant differences were also found between BMI groups when evaluating the Corpus Length variable, which serves as a good indicator of mandibular length. Our results indicate that as the BMI increases, corpus length also increases. Normal weight individuals have an average corpus length of (72.26), overweight individuals have an average corpus length of (75.43), and obese individuals have an average length of (77.5). Statistically, there is significant difference between normal weight individuals and overweight individuals, $(\mathrm{P}=0.013)$ and between normal weight individuals and obese individuals, $(\mathrm{P}=0.000)$ but not between overweight individuals and obese individuals.

Mandibular unit length, which was chosen as a check on corpus length, shows significant differences when related to BMI. Our results show that normal weight subjects have the shortest mandibles (120.71), overweight subjects have longer mandibles (124.51), and obese individuals have the longest mandibles (129.72). There was a significant difference between normal weight patients and overweight patients $(\mathrm{P}=0.047)$, between normal weight patients and obese patients $(\mathrm{P}=0.000)$ and between overweight patients and obese patients $(\mathrm{P}=0.031)$. None of the variable dealing with the vertical growth S-N to GoGn, mandibular plane, Y-Axis or MP-PP showed any significant differences. 


\section{Table 6:}

Variables Affecting Mean Craniofacial Measurements for Varying BMI's

Body Mass Index

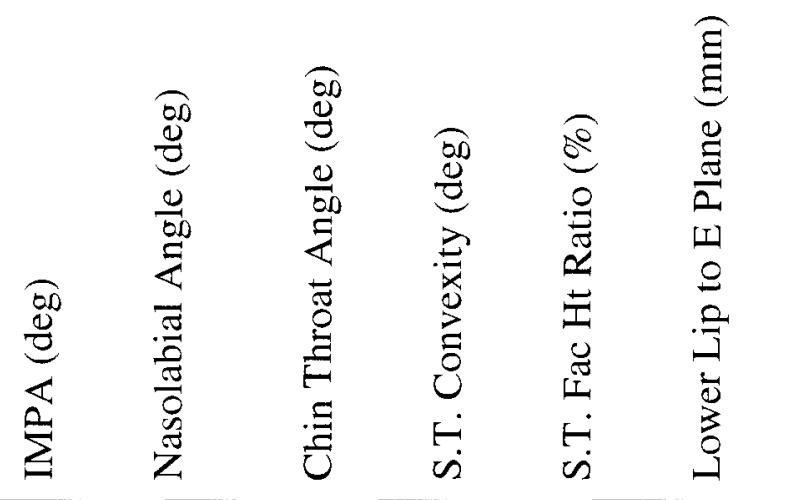

\begin{tabular}{lllllll}
\hline Normal Weight & & & & & & \\
Sample Size & 111 & 111 & 111 & 111 & 111 & 111 \\
Mean & 89.54 & 109.22 & 70.83 & 15.77 & 95.67 & 0.62 \\
Std. Dev & 7.68 & 17.11 & 10.60 & 11.25 & 11.95 & 5.09 \\
Over Weight & & & & & & \\
Sample Size & 19 & 19 & 19 & 19 & 19 & 19 \\
Mean & 87.90 & 103.90 & 69.27 & 11.80 & 89.45 & 0.38 \\
Std. Dev & 6.10 & 19.63 & 11.74 & 8.44 & 12.16 & 5.13 \\
Obese & & & & & & \\
Sample Size & 20 & 20 & 20 & 20 & 20 & 20 \\
Mean & 87.80 & 105.59 & 65.91 & 8.71 & 84.90 & -1.29 \\
Std. Dev & 7.34 & 12.95 & 15.14 & 5.22 & 11.16 & 5.38 \\
\hline
\end{tabular}

Table 6 lists the variable dealing with soft tissues compared against the different BMI groups. Only two of the dependant variables show a difference when compared in this manner. Soft tissue convexity shows a significant difference $(\mathrm{P}=0.018)$ between groups, with normal weight individuals having more convexity (15.77) than the obese individuals (8.71). Soft tissue facial height ratio also showed a significant difference $(\mathrm{P}=0.001)$ between normal and obese subjects. Normal weight subjects have a mean ratio of (95.67) and obese subjects have a mean ratio of (84.90). This indicates that the upper anterior vertical dimension of the face is smaller in relation to the lower anterior vertical 
dimension of the face in obese individuals when compared to normal weight individuals. None of the other soft tissue determinants, IMPA, nasolabial angle, chin throat angle, or lower lip to E-plane showed any statistically significant differences.

\section{Table 7:}

$\underline{\text { Variables Affecting Mean Craniofacial Measurements for Males and Females }}$

\begin{tabular}{|c|c|c|c|c|c|c|c|c|}
\hline Gender & 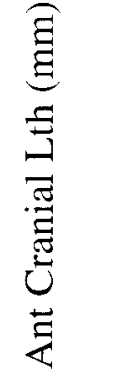 & 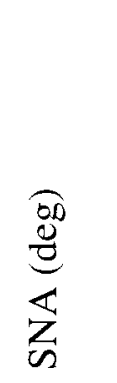 & 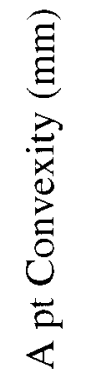 & 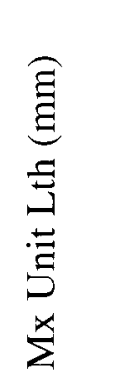 & 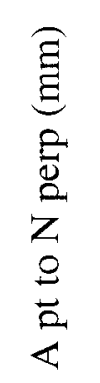 & 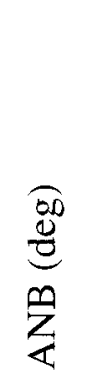 & 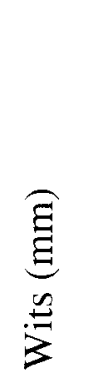 & 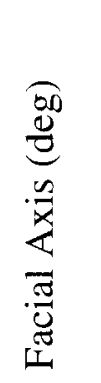 \\
\hline \multicolumn{9}{|l|}{ Male } \\
\hline Sample Size & 61 & 61 & 61 & 61 & 61 & 61 & 61 & 61 \\
\hline Mean & 61.15 & 82.74 & 3.47 & 98.07 & 0.21 & 4.05 & 1.33 & 88.24 \\
\hline Std. Dev. & 4.33 & 5.40 & 3.61 & 5.88 & 5.70 & 3.10 & 4.30 & 4.96 \\
\hline \multicolumn{9}{|l|}{ Female } \\
\hline$\overline{\text { Sample Size }}$ & 89 & 89 & 89 & 89 & 89 & 89 & 89 & 89 \\
\hline Mean & 57.71 & 83.00 & 3.00 & 95.15 & 2.09 & 3.52 & 0.18 & 89.21 \\
\hline Std. Dev. & 4.04 & 5.16 & 3.38 & 5.77 & 5.28 & 2.99 & 4.01 & 4.40 \\
\hline
\end{tabular}

All the measurements in Table 7 are related to the variability of the anterior cranium or maxilla in relation to gender. Anterior cranial length shows a significant difference $(\mathrm{P}=0.000)$ when compared on the basis of gender with the males having an average length of (61.15) and the females having an average length of (57.71). Maxillary unit length also shows a statistically significant difference $(\mathrm{P}=0.021)$ when compared on the basis of gender with the males having an average measurement of (98.07) and the 
females having an average measurement of (95.15). No significant differences were found between SNA, A pt. convexity, A-pt. to N perpendicular, ANB, the Wits measurement or the facial axis when compared on the basis of gender.

Table 8:

Variables Affecting Mean Craniofacial Measurements for Males and Females

\begin{tabular}{|c|c|c|c|c|c|c|c|}
\hline Gender & 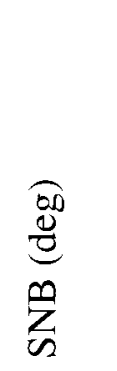 & 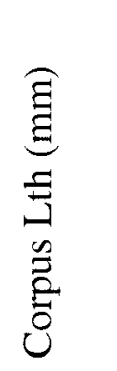 & 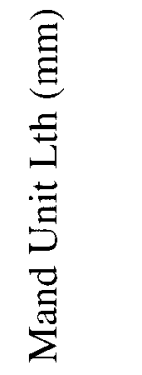 & 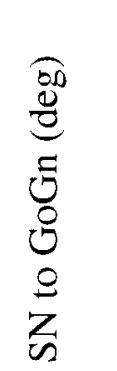 & 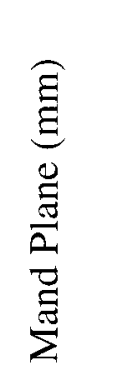 & 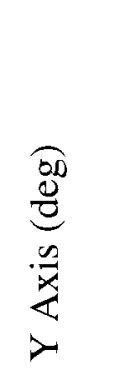 & $\begin{array}{l}\hat{a} \\
\hat{z}^{\prime}\end{array}$ \\
\hline \multicolumn{8}{|l|}{ Male } \\
\hline Sample Size & 61 & 61 & 61 & 61 & 61 & 61 & 61 \\
\hline Mean & 78.71 & 73.98 & 124.52 & 32.21 & 25.75 & 50.05 & 28.59 \\
\hline Std. Dev & 5.22 & 5.98 & 9.24 & 6.59 & 5.94 & 4.22 & 5.71 \\
\hline \multicolumn{8}{|l|}{ Female } \\
\hline Sample Size & 89 & 89 & 89 & 89 & 89 & 89 & 89 \\
\hline Mean & 79.46 & 72.94 & 120.93 & 32.46 & 23.83 & 57.11 & 27.95 \\
\hline Std. Dev & 4.71 & 5.17 & 7.40 & 5.58 & 5.61 & 3.86 & 5.80 \\
\hline
\end{tabular}

The measurements in Table 8 compare mandibular measurements on the basis of gender. Mandibular unit length not only shows a statistically significant difference when compared on the basis of BMI, but it also shows a difference $(\mathrm{P}=0.003)$ when compared on the basis of gender with males having an average length of $124.52 \mathrm{~mm}$ and females 
having an average of $120.93 \mathrm{~mm}$. SNB, corpus length, $\mathrm{SN}$ to GoGn, mandibular plane, Y Axis and MP - PP showed no differences when compared on the basis of gender.

\section{Table 9:}

Variables Affecting Mean Craniofacial Measurements for Males and Females

\begin{tabular}{|c|c|c|c|c|c|c|}
\hline Gender & 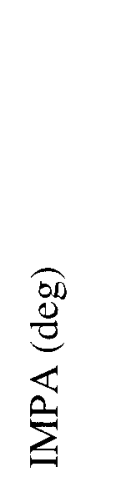 & 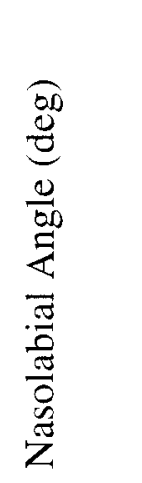 & 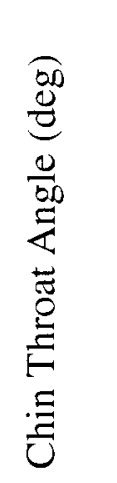 & 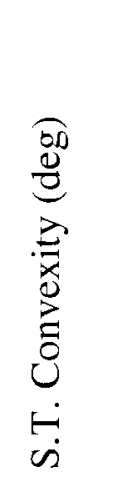 & 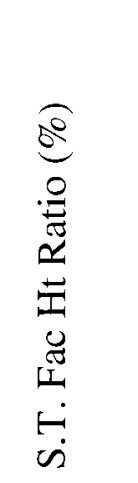 & 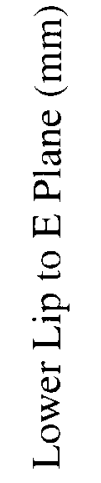 \\
\hline \multicolumn{7}{|l|}{ Male } \\
\hline Sample Size & 61 & 61 & 61 & 61 & 61 & 61 \\
\hline Mean & 89.06 & 109.41 & 67.41 & 16.28 & 90.79 & 0.59 \\
\hline Std. Dev. & 7.33 & 17.54 & 12.72 & 14.34 & 12.00 & 5.37 \\
\hline \multicolumn{7}{|l|}{ Female } \\
\hline$\overline{\text { Sample Size }}$ & 89 & 89 & 89 & 89 & 89 & 89 \\
\hline Mean & 89.13 & 107.14 & 71.74 & 12.98 & 95.27 & 0.16 \\
\hline Std. Dev. & 7.57 & 16.61 & 10.23 & 6.73 & 12.47 & 5.0 \\
\hline
\end{tabular}

Table 9 lists the variables dealing with soft tissues and compares them on the basis of gender. IMPA, nasolabial angle, chin throat angle, S.T. convexity, S.T. facial height ratio and lower lip to E-plane showed no statistical differences when compared on the basis of gender. 
Table 10:

Variables Affecting Mean Craniofacial Measurements for Different Age Groups

\begin{tabular}{|c|c|c|c|c|c|c|c|c|}
\hline Age in Years & 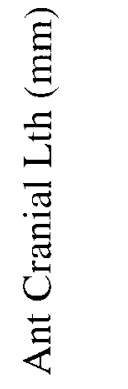 & 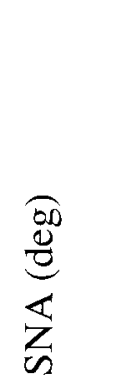 & 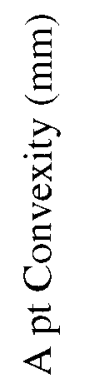 & 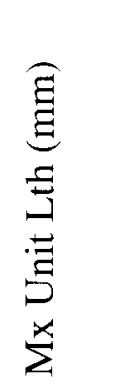 & 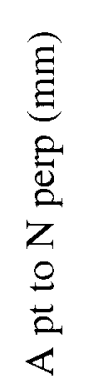 & 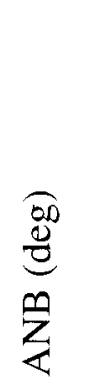 & 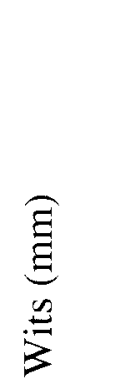 & 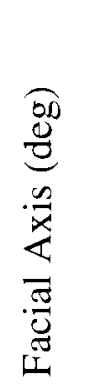 \\
\hline \multicolumn{9}{|l|}{ 4-10.9 } \\
\hline Sample Size & 30 & 30 & 30 & 30 & 30 & 30 & 30 & 30 \\
\hline Mean & 57.47 & 80.92 & 3.13 & 92.90 & 0.77 & 3.82 & 1.02 & 88.49 \\
\hline $\begin{array}{l}\text { Std. Dev } \\
11-12.9 \\
\end{array}$ & 4.46 & 4.94 & 3.61 & 6.52 & 5.73 & 3.49 & 4.93 & 5.05 \\
\hline Sample Size & 48 & 48 & 48 & 48 & 48 & 48 & 48 & 48 \\
\hline Mean & 58.65 & 83.86 & 4.13 & 96.68 & 2.81 & 4.52 & 1.34 & 88.75 \\
\hline $\begin{array}{l}\text { Std. Dev } \\
13-14.9 \\
\end{array}$ & 3.96 & 5.41 & 3.61 & 5.53 & 6.33 & 3.19 & 3.95 & 4.45 \\
\hline Sample Size & 51 & 51 & 51 & 51 & 51 & 51 & 51 & 51 \\
\hline Mean & 60.48 & 82.70 & 2.65 & 97.96 & 0.55 & 3.21 & -0.14 & 88.78 \\
\hline $\begin{array}{l}\text { Std. Dev } \\
15-20.0 \\
\end{array}$ & 4.04 & 4.87 & 3.13 & 5.73 & 4.84 & 2.61 & 3.91 & 4.62 \\
\hline Sample Size & 21 & 21 & 21 & 21 & 21 & 21 & 21 & 21 \\
\hline Mean & 59.16 & 83.85 & 2.41 & 96.52 & 0.62 & 3.10 & 0.49 & 89.52 \\
\hline Std. Dev. & 5.77 & 5.68 & 3.50 & 5.07 & 4.26 & 2.72 & 3.91 & 4.81 \\
\hline
\end{tabular}

All the measurements in table 10 are related to the variability of the anterior cranium or maxilla in relation to age. The maxillary unit length shows a considerable difference when comparisons between age groups are made. The significant difference is found between the subjects in the 4-10.9 year old group and the subjects in the 11-12.9 $(\mathrm{P}=0.028)$, and the $13-14.9(\mathrm{P}=0.001)$ year old group. The average length maxilla in those groups is $92.9 \mathrm{~mm}, 96.68 \mathrm{~mm}$ and $97.96 \mathrm{~mm}$ respectively. Anterior cranial length 
SNA, A pt. convexity, maxillary unit length, A pt. to N perpendicular, ANB, the Wits measurement and the facial axis showed no significant difference between age groups.

Table 11:

Variables Affecting Mean Craniofacial Measurements for Different Age Groups

\begin{tabular}{|c|c|c|c|c|c|c|c|}
\hline Age in Years & 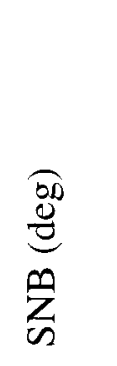 & 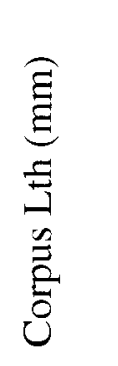 & 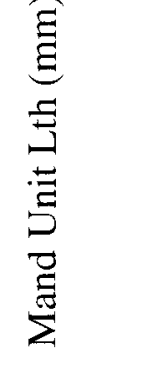 & 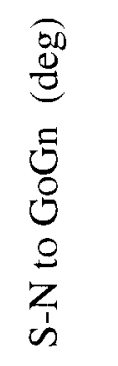 & 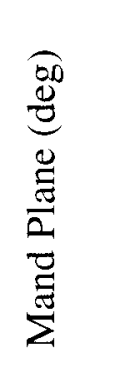 & 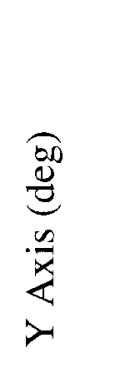 & 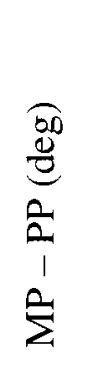 \\
\hline \multicolumn{8}{|l|}{ 4-10.9 } \\
\hline Sample Size & 30 & 30 & 30 & 30 & 30 & 30 & 30 \\
\hline Mean & 77.11 & 67.84 & 114.44 & 32.68 & 24.59 & 57.96 & 28.01 \\
\hline $\begin{array}{l}\text { Std. Dev } \\
11-12.9 \\
\end{array}$ & 4.50 & 4.39 & 7.77 & 6.14 & 5.77 & 4.59 & 5.75 \\
\hline$\overline{\text { Sample Size }}$ & 48 & 48 & 48 & 48 & 48 & 48 & 48 \\
\hline Mean & 79.18 & 72.76 & 121.02 & 32.21 & 24.43 & 58.05 & 27.96 \\
\hline $\begin{array}{l}\text { Std. Dev } \\
13-14.9 \\
\end{array}$ & 4.14 & 4.69 & 6.26 & 6.40 & 6.24 & 4.10 & 5.5 \\
\hline Sample Size & 51 & 51 & 51 & 51 & 51 & 51 & 51 \\
\hline Mean & 79.51 & 76.04 & 126.89 & 32.48 & 24.94 & 58.08 & 28.6 \\
\hline $\begin{array}{l}\text { Std. Dev } \\
15-20.0 \\
\end{array}$ & 4.85 & 4.52 & 6.99 & 5.76 & 5.52 & 3.73 & 6.2 \\
\hline$\overline{\text { Sample Size }}$ & 21 & 21 & 21 & 21 & 21 & 21 & 21 \\
\hline Mean & 81.15 & 76.10 & 125.94 & 31.93 & 24.28 & 57.03 & 28.10 \\
\hline Std. Dev. & 6.43 & 4.86 & 7.36 & 5.76 & 5.84 & 4.43 & 5.54 \\
\hline
\end{tabular}

The measurements in Table 11 compare mandibular measurements on the basis of age groups, and as would be expected, corpus length shows a significant difference when it is compared in this manner. The length continues to increase as the patient's age 
increases. The average length for the 4-10.9 year old is 67.84 , for the 11-12.9 year olds is $72.76 \mathrm{~mm}$, for the $13-14.9$ year olds is 76.04 and for the $15-20$ year olds is $76.10 \mathrm{~mm}$. The difference in length is statistically significant between each age group except between the 13.0-14.9 and the 15.0-20.0 age groups. The significance values are $(\mathrm{P}=0.000)$ between the 4.0-10.9 year olds and all the other age groups, $(\mathrm{P}=0.002)$ between the 11.0-12.9 and13-14.9 year olds, and $(\mathrm{P}=0.026)$ between the $11.0-12.9$ and 15.0-20.0 year olds.

The mandibular unit length, which is similar to corpus length, shows a statistically significant difference between age groups except between the 13.0-14.9 and the 15.0-20.0 age groups as well, with the length increasing with increasing age. The average length for the 4-10 year olds is $114.44 \mathrm{~mm}$, the $11-12.9$ year olds is $121.02 \mathrm{~mm}$, the $13-14.9$ year olds is 126.89 , and the $15-20$ year olds is $125.94 \mathrm{~mm}$. The significance values are $(P=0.000)$ between the 4.0-10.9 year olds and all the other age groups, $(P=0.000)$ between 11.0-12.9 and the 13.0-14.9 year olds, $(\mathrm{P}=0.020)$ between the $11.0-12.9$ and the 15.0-20.0 year olds. No significant differences were found between age and SNB, S-N to GoGn, mand. plane angle, Y Axis or MP-PP, but there was interaction between gender and age groups when comparing the dependant variable MP-PP. 
Table 12:

Variables Affecting Mean Craniofacial Measurements for Different Age Groups

\begin{tabular}{|c|c|c|c|c|c|c|}
\hline Age in Years & 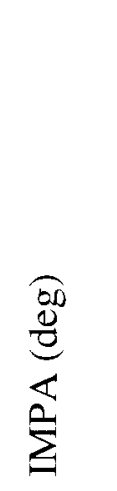 & 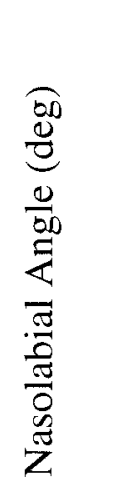 & 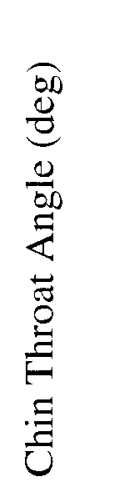 & 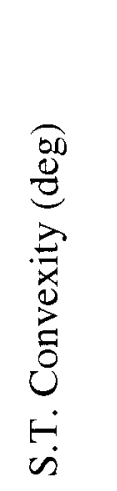 & 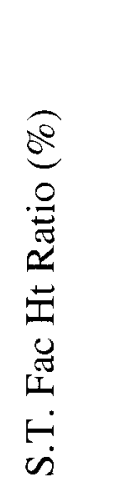 & 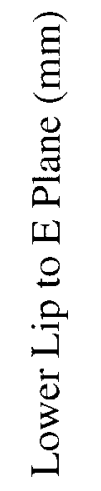 \\
\hline \multicolumn{7}{|l|}{$4-10.9$} \\
\hline$\overline{\text { Sample Size }}$ & 30 & 30 & 30 & 30 & 30 & 30 \\
\hline Mean & 88.11 & 112.58 & 68.62 & 13.34 & 97.12 & -0.49 \\
\hline $\begin{array}{l}\text { Std. Dev. } \\
11-12.9\end{array}$ & 6.60 & 14.47 & 12.99 & 7.82 & 13.25 & 3.14 \\
\hline$\overline{\text { Sample Size }}$ & 48 & 48 & 48 & 48 & 48 & 48 \\
\hline Mean & 90.63 & 105.83 & 69.12 & 15.53 & 92.62 & 0.61 \\
\hline $\begin{array}{l}\text { Std. Dev } \\
13-14.9\end{array}$ & 8.08 & 17.10 & 10.29 & 6.52 & 13.59 & 5.73 \\
\hline Sample Size & 51 & 51 & 51 & 51 & 51 & 51 \\
\hline Mean & 88.17 & 108.70 & 70.43 & 14.69 & 92.61 & 1.01 \\
\hline $\begin{array}{l}\text { Std. Dev. } \\
15-20.0\end{array}$ & 7.21 & 18.87 & 11.05 & 15.51 & 10.80 & 5.83 \\
\hline Sample Size & 21 & 21 & 21 & 21 & 21 & 21 \\
\hline Mean & 89.31 & 105.19 & 72.78 & 12.09 & 92.11 & -0.75 \\
\hline Std. Dev. & 7.56 & 14.59 & 12.99 & 5.93 & 12.11 & 4.09 \\
\hline
\end{tabular}

Table 12 lists the variable dealing with soft tissues and compares them on the basis of age groups. Neither IMPA, nasolabial angle, chin throat angle, soft tissue convexity, soft tissue facial height ratio or lower lip to E plane show any significant difference between age groups. 


\section{DISCUSSION}

The Body Mass Index (BMI) rating system was used to categorize subjects into one of three groups, because it is a well recognized and accepted system for approximating body composition. In addition, delineations between groups are well defined in the literature.[12] Besides analyzing our data by comparing individuals with differing BMI's we also compared the individuals by gender. This was done to determine which, if any, craniofacial measurements were related to gender in the age groups examined. We further compared different age groups to determine if age impacted the size of, or relationships between, craniofacial structures.

Our results substantiated the findings of the previously conducted studies. Paoli et al., conducted a similar study in 2001 to determine if obesity contributed to the occurrence of OSA. Using 31 measurements, he concluded that the obese group had longer cranial bases, longer mandibles and smaller ANB angles.[9] In March 2003, Ferrario et al., using 50 soft tissue landmarks, concluded that obese individuals have wider skulls bases and mandibles. They have deeper mid and lower faces with longer mandibles and shorter upper faces than their non-obese counterparts.[10] In our study, we found that obesity significantly affects a variety of craniofacial structures including, SNA, Maxillary Unit Length, SNB, Corpus length, Mandibular Unit length, ST Convexity and ST Facial Height Ratio, while having no effect on others. 
We chose specific linear and angular measurements on the lateral cephalometric radiograph in order to represent most of the important measurements, including hard and soft tissues, evaluated during routine orthodontic treatment planning. When undertaking the treatment planning phase of orthodontics, many orthodontists find the following measurements useful:

$\underline{\mathrm{S}-\mathrm{N}}$

Both sella and nasion are easily located on most lateral cephalometric radiographs, allowing this line to be drawn relatively consistently. Originally used in the Steiner analysis of the 1950's and still in use today, it provides a reliable and objective means for measuring the cranial base. The critics of this measurement however, contend that the position of sella varies from patient to patient making this an unreliable reference plane and prefer to use the Frankfort horizontal as their reference plane instead. As with many other cephalometric analysis, it is unknown exactly how Steiner determined his norms, therefore comparisons were made between one subject group and another rather than between subject groups and a norm.[13]

In our study, this dependant variable did not vary significantly with different levels of BMI, but differed significantly with differences in gender. On average the males had an anterior cranial length $5 \mathrm{~mm}$ longer than the females. We did not find any significant differences in the S-N measurement when comparisons were made based on age. 
SNA also originated as part of the Steiner analysis in the 1950's and is still widely used and well understood. It indicates the relative protrusiveness of the maxilla, and the points are easy to locate. Its weakness lies in the variability of the Sella position.[13]

In our study, SNA was found to be significantly affected by obesity, but we found conflicting results. We found that there was a statistically significant difference between normal BMI individuals and over weight individuals with regard to SNA, but not between normal BMI individuals and obese individuals, or between over weight individuals and obese individuals. Therefore, it is difficult to draw a definite conclusion.

This dependant variable did not differ significantly in our study when compared on the basis of gender or age.

\section{A-point Convexity}

A point convexity was selected to use in the study as a linear check on the angular measurement SNA. Dr. Robert Ricketts first used it in his bioprogressive analysis of 1960 which predicted growth. Ricketts' norms were developed by evaluating 1000 consecutive cases with "usual" orthodontic problems from his private office.[13]

In our study, this dependant variable did not vary significantly when compared on the basis of BMI, gender or age.

\section{Maxillary Unit Length}

Harvold first used maxillary unit length in his analysis in 1974 to demonstrate the skeletal changes that took place after using functional appliances. He used this particular measurement to determine the anterior-posterior length of the maxilla. His norms were developed by the Burlington Growth Study, in which the subjects were predominantly 
children of Northern European decent with both malocclusions and ideal occlusions.[13] Maxillary unit length differed significantly with variations in BMI. We found a significant difference between normal BMI patients and obese patients with the obese group having significantly longer maxillas than the normal weight group. The over weight patients tended to have longer maxillas than the normal BMI patients on average, but the results were not statistically significant. In this study we found that maxillay unit length is directly related to BMI and as body mass increases so too does the length of the maxilla.

Maxillary unit length also differed significantly when compared on the basis of gender. The male mean was $98 \mathrm{~mm}$ and the female mean was $95 \mathrm{~mm}$. This was not surprising, since males tend to be larger overall and to have larger bone structure.

We also found significant differences in maxillary unit length when comparing individuals in different age groups. As the groups progress in age their average maxillary unit length also increases except for the 15-20 year old group whose average is $0.5 \mathrm{~mm}$ less than the 13-14 year old group. This agrees with previously published reports of normal growth in this area of approximately $1.0 \mathrm{~mm}$ per year.[14] Although our study was not longitudinal, the average length of the maxilla appeared to increase with age.

\section{A to $N$ perp}

This measurement was introduced in July 1982 at the University of Michigan as part of the McNamara Analysis. This analysis was developed because the other cephalometric analyses were developed in the 1940's, 50's and 60's prior to the use of orthognathic surgery or functional appliances. McNamara contended that the new found ability to move bony structures, which began in the 1980's, created the need for a new 
cephalometric analysis. His normative sample was compiled data from three groups, giving him a large and very diverse set of norms. The first sample was of children in the Bolton Brush Growth Study who were followed from 6 to 18 years old. The second group was comprised of children seen in the Burlington Growth Center from 6 to 20 years of age. The last group was comprised of 111 children from Ann Arbor, Michigan who were determined to have good to excellent facial configurations by McNamara and his colleagues.[13]

In our study, this dependant variable did not vary significantly when compared on the basis of BMI, gender or age.

$\underline{\text { Summary of maxillary measurements }}$

Based on the results of the three dependent variables listed above describing maxillary protrusion it appears that maxillary prognathism is independent of BMI. This contradicts the study performed by Ohrn et al., in which she concluded that both jaws of the obese patients were prognathic.[11] She relied on only one measurement, SNA, to estimate the anterior-posterior positioning of the maxilla. Our study used three measurements, two of which indicated that the maxilla was no more prognathic in obese patients than in the normal weight patients, while SNA gave mixed results. We did, however, find that the anterior-posterior length of the maxilla was significantly greater in obese patients than in normal BMI patients, but this greater length did not result in a more anteriorly positioned maxilla.

$\underline{\mathrm{ANB}}$

ANB, found in the Steiner analysis, is commonly used in orthodontic treatment planning even though the variable anterior-posterior positioning of nasion alters the 
consistency of the measurement. The norm was derived from the Steiner model as described above.

In our study this dependant variable did not vary significantly when compared on the basis of BMI, gender or age.

$\underline{\text { Wits }}$

The Wits analysis is generally used to verify the accuracy of ANB which has inherent inaccuracies in a certain small percentage of patients whose $\mathrm{N}$ point is either abnormally anteriorly or posteriorly positioned. Dr. Jacobon first published the analysis in 1975 at the University of Witwaterstrand in Johannesburg, South Africa. The cant of the occlusal plane influences this measurement; therefore the measured relationship of the maxilla to the mandible will vary with an excessively tipped occlusal plane. Norms for this analysis were based on 21 males and 21 females with "excellent" occlusion.[13]

In our study this dependant variable did not vary significantly when compared on the basis of BMI gender or age.

\section{$\underline{\text { Facial Axis }}$}

Facial Axis is a measurement developed by Ricketts to measure the vertical direction of the growing mandible. A smaller angle suggests a growth pattern which will result in a shorter mandible with a class II profile, while a larger angle results in a longer mandible and a class III profile. Again this "norm" was developed from 1,000 consecutive cases treated by Ricketts. He used this angle to determine the effect of his treatment. He indicated that even with age this angle would not change unless active orthodontics were undertaken.[13] 
We did not find any significant difference between facial axis measurements when compared on the basis of BMI, gender or age. Finding no significant differences between age groups when evaluating the facial axis or the y axis, both of which measure nearly the same dimension is consistent with previously reported data. Dr. Ricketts used the facial axis angle to determine the effect of his treatment. He indicated that facial axis as well as the inclination of the lower incisors does not change with age. Our results agree with his conclusion, as we found no significant differences in either measurement when the comparisons were based on age.

$\underline{\mathrm{SNB}}$

SNB is a component of the Steiner analysis (Steiner norms), but its weakness is the unfortunately high variability in the position of sella.

In our study, SNB, an indicator of mandibular prognathism, showed a significant difference when compared on the basis of BMI. Our results showed a direct relationship between BMI and SNB. These results are in agreement with the other measurements related to mandibular prognathism, as well as with the results of studies performed previously by Ohrn et al., and Paoli et al. Ohrn concluded that the mandible exhibited an increased prognathism in obese patients of both genders,[11] and Paoli reached similar conclusions stating that normal weight individuals have smaller SNB angles when compared to obese individuals.[9]

In our study SNB did not significantly differ based on gender or age. 


\section{Corpus Length}

Corpus length, from Ricketts' bioprogressive analysis (Rickett norms), is a measurement of the body of the mandible in the sagittal plane. It uses the constructed Xi point as its posterior limit and Pm point as its anterior limit.[13]

Corpus length, a measurement of the length of the body of the mandible, was significantly different between normal weight and obese patients. As BMI increased corpus length also increased. This finding was consistent in all the studies done comparing this measurement in patients with varying BMIs. Both Paoli [9] and Ohrn [11] came to similar conclusions. Ohrn concluded that the dependant variable differing the most in relation to BMI was the length of the mandible.[11] Our results yielded an average difference of $3 \mathrm{~mm}$ and $5 \mathrm{~mm}$ between normal weight patients and over weight patients, and between normal weight patients and obese patients respectively.

Although not significant, males did have a longer corpus length measurement on average $(74 \mathrm{~mm})$ than females $(73 \mathrm{~mm})(\mathrm{P}=0.145)$.

Corpus length, an indicator of mandibular growth, varied significantly between age groups. This concurs with previously published growth statistics that indicate that the length of the mandible will increase a little less than $2 \mathrm{~mm}$ per year between the ages of 6 and 16.[14]

\section{Mandibular Unit Length}

Harvold (Harvold norms) first published his analysis, including mandibular unit length, in 1974.[13] It is a similar measurement to corpus length as described above. Since we saw a significant difference in one of these measurements we would expect to see a significant difference in the other as well. 
In our study, mandibular unit length showed similar results to corpus length when compared on the basis of BMI. Since these measurements both evaluate mandibular length the similarity in results was expected. We found that the mandibular unit length measurement increased with increasing BMI. This measurement differed significantly by gender as well. Males had an average length of $125 \mathrm{~mm}$ and females had an average length $121 \mathrm{~mm}$.

Mandibular unit length, another indicator of mandibular growth, varied significantly between age groups also. This concurs with previously published growth statistics that indicate that the length of the mandible will increase a little less than $2 \mathrm{~mm}$ per year between the ages of 6 and 16.[14]

\section{$\underline{\mathrm{S}-\mathrm{N} \text { to GoGn }}$}

$\mathrm{S}-\mathrm{N}$ to GoGn is from the Steiner analysis (Steiner norms). It measures the vertical growth of the mandible. Larger angles suggest a retrognathic mandible and anterior open bite, while smaller angles indicate a prognathic mandible and deep bite. Its weakness, like other measurements that incorporate $\mathrm{S}-\mathrm{N}$ is the variability of sella.

We did not find a significant difference between S-N to GoGn when comparisons were based on BMI gender or age.

\section{$\underline{\text { FMA }}$}

FMA is one of the three angles that make up the Tweed triangle, and also measures the inclination of the mandibular plane similar to S-N to GoGn. Tweed used the Frankfort Horizontal reference plane rather than S-N reference plane. For his norms Tweed used 100 of his own cases with satisfactory facial esthetics and 3,500 of the 
Bolton-Brush subjects who had satisfactory and unsatisfactory esthetics for his normative values.[13]

We did not find a significant difference between BMI and FMA, which agreed with our results for the $\mathrm{S}-\mathrm{N}$ to GoGn measurement. These values both measure mandibular angulation, and neither showed any relationship to BMI. Ohrn, however, found the mandibular plane angle significantly decreased in obese female patients,[11] but did not evaluate S-N to GoGn or the facial axis.

In our study, the FMA did not differ significantly when based on gender or age. Ricketts, however, predicted that FMA decreases by one degree every three years.[14] Our sample may have been too small to detect such a small change over such a long period.

$\underline{Y-a x i s}$

Found in the Down's analysis (Downs norms), the $\mathrm{Y}$ axis is closely related to the Ricketts' facial axis angle. This angle increases as the mandible becomes more retrognathic and the class II profile becomes more pronounced.

We did not find a significant difference between the $y$-axis when measurements were based on BMI, gender or age.

$\underline{\mathrm{MP}}-\mathrm{PP}$

The intersection of the MP and PP lines measures the angular relationship between the palatal plane and the mandibular plane and is a component of the 1955 Sassouni analysis. He does not present norms with this study but rather standardizes relationships between the measurements of each individual patient, so each patient measured will have their own distinct set of norms.[13] 
We did not find a significant difference between MP -PP measurements when comparisons were made on the basis of BMI gender or age.

IMPA

Found in the Down's analysis, IMPA was one of the first measurements made using lateral cephalometric radiographs. It describes the relationship between the mandibular incisor teeth and the mandibular basal bone. Downs selected 20 Caucasian children, 10 males and 10 females, age 12 to 17 who were judged to have excellent occlusion to develop his norms.[13]

We did not find a significant difference between IMPA measurements when the comparisons were based on BMI, gender or age. Ricketts indicated that the inclination of the lower incisors does not change with age, and our results, which showed no significant difference between age groups, agree with that conclusion.[14]

\section{$\underline{\text { Nasolabial Angle }}$}

Nasolabial angle measures the soft tissue prominence in the area of the upper lip and is a component of the McNamara analysis (McNamara norms). A large obtuse angle indicates a "tipped up nose" or a lack of anterior development of the maxilla, while an acute angle indicates excessive fullness in the anterior maxilla or a "low hanging nose". This angle is easily determined and is usually evaluated if extractions are a possibility.[13]

We did not find a significant difference in nasolabial angle when the comparisons were based on BMI, gender or age. 


\section{Chin Throat Angle}

Chin throat angle is a measurement used in the Moshiri surgical analysis. More obtuse angles suggest the deposition of adipose tissue in the submental area. To develop his norms Dr. Moshiri chose 50 Caucasian and 50 African Americans between the ages of 18 and 50 years. All subjects had "balanced profiles" and were skeletal and dental class I's. Sexual differentiation was included in the set of norms.[15]

Surprisingly we did not find a significant difference in chin throat angle when the comparisons were based on BMI, and the average angle decreased with increased BMI (normal 70.84, over weight 69.27 , obese 65.91 ). This was most likely caused by the difficulty in consistently drawing a line tangent to the submandibular soft tissue. The large standard deviation associated with this measurement indicates that there is considerable variability in it. The angle between the ramus and body of the mandible, appears to be unaffected by variations in BMI and could potentially alter the chin throat angle.

We did not find a significant difference between chin throat angles when comparisons were made based on gender or age.

\section{$\underline{\text { Soft Tissue Convexity }}$}

Soft tissue convexity is a measurement from the Legan analysis of 1980. Legan concentrated solely on the soft tissue and contended that the soft tissue should be the primary point of focus. This measurement describes the sagittal relationship of the maxilla to the mandible. The norm for this measurement was taken from a group of 40 white subjects, 20 males and 20 females, between the ages of 20 and 30 who were 
determined to nave normal anterior vertical relationships and untreated class I occlusion.[13]

Soft tissue convexity defines the soft tissue anterior-posterior position of the mandible in relation to the upper facial plane. In our study, it was significantly different when comparing non-obese patients to those who were obese. As expected if obese subjects have longer more prognathic mandibles, they should also have smaller soft tissue convexities. Although this particular measurement was not evaluated in any of the studies referenced, it does seem to be in agreement with the other studies that concluded that the mandible is larger and more anteriorly placed in the obese population when compared to the non-obese population.[10], [11]

We did not find a significant difference between soft tissue convexity measurements when comparisons were made based on gender or age.

\section{$\underline{\text { Soft Tissue Facial Height Ratio }}$}

Soft tissue facial height ratio is used in the Legan analysis in which a well balanced face in the vertical dimension is a $1: 1$ ratio.[13] If the ratio is not within two standard deviations of the $1: 1$ norm, both measurements must be evaluated to determine which one is at fault. The normative sample is the same as that described for soft tissue convexity.

We also found that the soft tissue facial height ratio was significantly different between the different BMI groups. The normal weight group had a longer upper anterior face height in relation to their lower anterior facial height than did the obese group. Although this measurement was not evaluated in any of the previous studies reviewed, the study performed by Ferrario concluded that obese individuals had decreased upper 
facial heights.[10] This substantiates our results and explains the differences seen between the groups with regard to the soft tissue facial height ratios.

We did not find a significant difference between soft tissue facial height ratios when the comparisons were based on gender or age.

\section{Lower Lip to E-Plane}

Lower lip to E-Plane indicates incisor and lower lip protrusion. The norms are based on the same subjects as those used for the soft tissue facial height ratio measurement.

No significant differences were found between lower lip to E-plane measurements when comparisons were based on BMI, gender or age.

Dentofacial Planner Plus version $2.5 \mathrm{~b}$ was used to digitize the lateral cephalometric radiographs and measure the 21 areas of interest. Dempsey Smith et al., (2004) compared it to the other lateral cephalometric tracing programs. He found that Dentofacial Planner ranked the highest of five programs in its ability to predict surgical outcomes, and ranked first in almost all other categories evaluated.[16] The limiting factor in the accuracy of the tracings and measurements however, are the radiographs themselves and the investigator's ability to accurately choose the points consistently. The computer simply calculates the linear and angular measurements based on the chosen points. The clarity of the radiographs and the positioning of the patient were potential sources of inaccuracies, but we standardized the process and limited the number of assistants exposing the radiographs to reduce this source of error as much as possible.

Although individuals vary, males and females reach puberty at different ages; therefore four age groups were defined: 4-10.9, 11-12.9, 13-14.9 and 15-20 years. 
The independent variable BMI significantly affected most craniofacial measurements, 7 total out of 21 , while gender and age only significantly affected three apiece. Importantly, obesity had a greater affect on the craniofacial structures studied in the range of 4-20 years than either gender or age, two variables assumed to have a dramatic effect on the craniofacial structure. 


\section{CONCLUSION}

1. Increased BMI significantly affects the SNA measurement; larger values are seen in overweight individuals with significant differences between the norm and overweight.

2. Increased BMI significantly affects maxillary unit length; larger values are seen in overweight and obese individuals, with a significant difference between the norm and obese.

3. Increased BMI significantly affects the SNB measurement with larger values seen in overweight and obese individuals. Significant differences were seen between the norm and the overweight groups and between the norm and the obese groups.

4. Increased BMI significantly affects corpus length with larger measurements seen in the overweight and the obese groups. Significant differences were seen between the norm and the overweight groups and between the norm and the obese groups.

5. Increased BMI significantly affects the mandibular unit length with larger values seen in the overweight and the obese groups. Significant differences were seen between the norm and the overweight groups, between the norm and the obese groups and between the overweight and the obese groups. 
6. Increased BMI significantly affects soft tissue convexity with smaller values seen in the overweight and obese groups. Significant differences were seen between the norm and the obese groups.

7. Increased BMI significantly affects the soft tissue facial height ratio in an inverse relationship. Significant differences were seen between the normal weight and the obese groups.

8. Gender affects the $\mathrm{S}-\mathrm{N}$ measurement with males having a significantly longer anterior cranial base.

9. Gender affects the maxillary unit length with males having a significantly longer maxilla.

10. Gender affects mandibular unit length with males having a significantly longer mandible.

11. Age affects the maxillary unit length with the older groups having longer maxillas. Significant differences were seen between the 4-10 yr olds and the 11$12 \mathrm{yr}$ olds and the 13-14 yr olds.

12. Age affects the corpus length with the older groups having the greater measurement with a significant difference between all the age groups except the $13-14$ and the 15-20.

13. Age affects the mandibular unit length with the older groups having the greater measurement with a significant difference between all the age groups except the 113-14 and the 15-20. 


\section{SUMMARY}

As orthodontists, this information is useful because it helps in the diagnosis and treatment planning of our patients. Our study indicates that overweight/obese children tend to have accelerated bone growth in both the maxilla and the mandible. Although the increased growth does not manifest itself as a more anteriorly placed maxilla, it does manifest itself as a more anteriorly placed mandible. This results in overweight/obese children presenting with a tendency for a class III skeletal relationship. It is unknown if this relationship corrects itself as the patients progress into adulthood; this is a question that requires further study. If it is determined that the class III tends to resolve on its own, aggressive treatment prior to growth cessation may not be warranted. In the case of an overweight/obese adolescent with a mild class III tendency, the problem may be expected to self correct without any special orthodontic appliances. If, after further research, it is determined that the class III does not tend to resolve on its own, then more aggressive treatment may be warranted at an earlier age. 


\section{REFERENCES}

1. Thorpe L., List D., Marx T., May L., Helgerson S., Frieden T., Childhood Obesity in New York City Elementary School Students. American Journal of Public Health, 2004. 94(9): p. 1496-1500.

2. Ebbeling C., Pawlak D., Ludwig D., Childhood Obesity: Public-Health Crisis, Common Sense Cure. The Lancet, 2002. 360: p. 473-479.

3. Yensel C., Preud'Homme D., Curry D., Childhood Obesity and Insulin-Resistant Syndrome. Journal of Pediatric Nursing, 2004. 19(4): p. 238-246.

4. Morgan C., Tanofsky-Kraff M., Wilfley D., Yanovski J., Childhood Obesity. Child Adolesc Psychiatric Clin N Am, 2002. 11: p. 257-278.

5. Fauci, Braunwald, Isselbacher, Wilson, Martin, Kasper, Hauser, Longo, Harrison's Principles of Internal medicine $14^{\text {th }}$ Ed. 1998, New York: p. 203, $2061,2106,1718,1420$.

6. Description of Blount's Disease, Available at http://wwmlm.nih.gow/medlineplus/encv/article/(0)1584.htm. Accessed March 1, 2005. 2005.

7. Reilly J., Methven E., McDowell Z., Hacking B., Alexander D., Stewart L., Kelnar C., Health Consequences of obesity. Arch Dis Child, 2003. 88: p. 748-752.

8. Xiujun Y., Keisaku F., Kazuhisa U., Yukinori M., Keishi K., CephalometricAnalysis in Obese and Nonobese Patients With Obstructive Sleep Apnea Syndrome. Chest, 2003. 124: p. 212-218.

9. Paoli J., Lauwers., Lacassagne L., Tiberge M., Dodart L., Boutault F., Craniofacial Differences According to the Body Mass Index of Patients with Obstructive Sleep Apnea Syndrome: Cephalometriv Study in 85 Patients. British Journal of Oral and Maxillofacial Surgery, 2001. 39: p. 40-45.

10. Ferrario V., Dellavia C., Tartaglia G., Turci M., Storza C., Soft Tissue Morphology in Obese Adolescents: A Three Dimensional Noninvasive Assessment. Angle Orthodontist, 2004. 74(1): p. 37-42. 
11. Ohrn K., Al-Kahlini B., Huggare J., Forsberg C., Marcus C., Dahllof G., Craniofacial Morphology in Obese Adolescents. Acta Odontol Scand, 2002. 60: p. 193-197.

12. National Center for Disease Prevention and Health promotion. BMI defined,

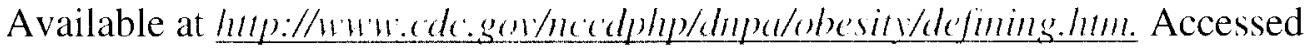
November 15, 2004. 2004.

13. Schuler, J., Introduction to Cephalometric Diagnosis. University of Louisville School of Dentistry, Department of Orthodontics, 2003. p.46, 35, 77, 74, 102, 95 , $90,89,74,57,62,39,111,38,114,115$.

14. Jacobson A., Radiographic Cephalometry. 1995, Carol Stream, IL: Quintessence. p. $149,92,139$.

15. Connor A., Moshiri F., Orthodontic Surgery Norms for American Blacks. AJO, 1985. 87(2): p. 119-134.

16. Smith J., Thomas P., Proffit R., A Comparison of Current Prediction Imaging programs. American Journal of Orthodontics and Dentofacial Orthopedics, 2004. 125(5): p. 527-536.

17. Daskalogiannakis J., Glossary of Orthodontic Terms. 2000, Chicago: Quintessence.

18. Ehtisham S., Barrett T., The Emergence of Type 2 Diabetes in Childhood. Ann Clin Biochem, 2004. 41: p. 10-16.

19. Hardy R., Wadsworth M., Langenberg C., Kuh D., Birthweight, Childhood Growth and Blood Pressure at 43 Years in a British Birth Cohort. International Journal of Epidemiology, 2004. 33: p. 121-129.

20. Raman R., Obesity and Health Risks. Journal of the American College of Nutrition, 2002. 21(2): p. 134S-139S.

21. Lai S., Ng K., Lin H., Chen H., Association Between Obesity and Hyperlipidemia Among Children. Yale Journal of Biology and Medicine, 2001. 74: p. 205-210.

22. Poulter N., Childhood Obesity: An Emerging Public-health Problem. The Lancet, 2001. 357: p. 1989-1992.

23. Ball G., McCargar L., Childhood Obesity in Canada: A Review of Prevalence Estimates and Risk Factors for Cardiovascular Disease and Type 2 Diabetes. Can. J. Appl. Physiology, 2003. 28(1): p. 117-140. 
24. Flodmark C., Lissau I., Moreno L., Pietrobelli A., Widhalm K., New Insights into the Field of Children and Adolescents' Obesity: The European Perspective. International Journal of Obesity, 2004. 28: p. 1189-1196.

25. Rugg K., Childhood Obesity: Its Incidence, Consequences and Prevention. Nursing Times, 2004. 100(3): p. 28-30.

26. Ono T., Lowe A., Ferguson K., Fleetham J., Associations among Upper Airway Structures, Body Position, and Obesity in Skeletal Class I Male Patients with Obstructive Sleep Apnea. AJO, 1996. 109(6): p. 625-634.

27. Tangugsorm V., Krogstad O., Espeland L., Lyberg T., Obstructive Sleep Apnoea: Multiple Comparisons of Cephalometric Variables of Obese and Non-obese patients. Journal of Cranio-Maxillofacial Surgery, 2000. 28: p. 204-212.

28. Sakakibara H., Tong M., Matsushita K., Hirata M., Konishi Y., Suetsugu S., Cephalometric Abnormalities in Non-obese and Obese Patients with Obstructive Sleep Apnoea. Eur Respir J, 1999. 13: p. 403-410.

29. Johns F., Strollo P., Buckley M., Constantino J., The Influence of Craniofacial Structure on Obbstructive Sleep Apnea in Young Adults. J Oral Maxillofac Surg, 1998. 56: p. 596-602.

30. Tangugsorm V., Krogstad O., Espeland L., Lyberg T., Obstructive Sleep Apnea: A Canonical Correlation of Cephalometric and Selected Demographic Variables in Obese and Nonobese Patients. Angle Orthodontist, 2001. 71(1): p. 23-35. 


\title{
CURRICULUM VITAE
}

\author{
Daniel Mark Eves \\ 8214 Camberley Drive \\ Louisville, KY 40222 \\ $502-852-2829(\mathrm{w})$ \\ 502-749-5050 (h) \\ dmeves01@louisville.edu
}

\section{EDUCATION:}

July 2003 - Present University of Louisville, Louisville, KY

Orthodontic Certificate and Masters of Science in Oral Biology Candidate

May 1999 University of Florida, Gainesville, FL

D.M.D.

Honors: Dean's List, Summer 1998

Offices Held: American Student Dental Association, Class

Representative

G.P.A. 3.54

May 1996 Providence College, Providence, RI

M.B.A.

G.P.A. 3.83

May 1986

United States Naval Academy, Annapolis, MD

B.S.

Area of Concentration: Engineering

\section{AWARDS:}

Elected to membership in Omicron Kappa Upsilon Omicron Kappa Upsilon Student Ethics Award Annual Student Award of the American Academy of Periodontology Three year Armed Forces Health Professions Scholarship 


\section{PROFESSIONAL EXPERIENCE:}

July 2002 - June 2003

United States Navy, Jacksonville, NC Director Camp Geiger Dental Clinic

Responsible for the proper functioning of all aspects of the clinic while maintaining a full load of patients. Manages a staff of five including civilians and naval personnel.

September 2000 - June 2002 United States Navy, Camp Lejeune, NC

Officer, U.S. Naval Dental Corps.

Performed duties of general dentist and collateral duties as Training Officer, Records Review Officer, Process Improvement Coordinator and physical fitness coordinator.

July 1999 - August 2000 Bethesda, MD
United States Navy, National Naval Medical Center, General Practice Resident

Performed wide scope of dental procedures including Orthodontics, Anesthesia, Oral Surgery, Periodontics, Endodontics, Prosthodontics, and Operative Dentistry.

October 1992 - May 1995 United States Navy, Naval Education \& Training Center, Newport, RI

\section{Director, Instructor Training School}

Led staff, which included two other officers, in training of all naval officer instructors for the entire base and throughout the East Coast.

December 1989 - October 1992 United States Navy, Beach Masters Unit Two, Little Creek, VA

\section{Officer in Charge, Stinger Missile Detachment}

Supervised team of thirty senior and junior enlisted personnel in defending US Naval vessels against specific air attack threats, most notably during Operation Desert Storm.

May 1986 - December 1989 United States Navy, USS Mount Vernon, San Diego, CA Division Officer

Supervised team of fifteen senior and junior enlisted personnel responsible for the proper functioning and maintenance of boilers, main engines and all associated auxiliary equipment. 


\section{RESEARCH PRESENTED AT CONFERENCE:}

Active Spring Retainer for Mandibular Incisors. Table clinic presented at the Mid Atlantic Armed Forces Dental Conference, Washington, D.C., May 2000.

\section{PROFESSIONAL MEMBERSHIPS:}

United States Naval Dental Corps

American Dental Association

American Association of Orthodontists

Academy One Hundred

University of Florida Dental Alumni Association

\section{RELATED EXPERIENCE:}

- Postgraduate Orthodontic Residency at the University of Louisville

- Attended five day orthodontic and pediatric dentistry CE course.

- Coordinated and delivered orthodontic training to AEGD residents.

- Monthly sessions with local orthodontists

Meet to discuss treatment options and review case studies.

- Presentations to Oral Surgery and GPR staff and residents at National Naval Medical Center

Included topics such as Oroantral Fistula, Hypertension, Pericoronitus, Adrenal Insufficiency, Seizures, Salivary Gland Diseases, Crohn's Disease, Odontogenic Infections and Heparin Window.

- Humanitarian trip to Dominican Republic

Performed dental services for residents without access to regular care. Included multiday excursions to remote locations as well as setup and coordination of "outdoor operatories".

- American Student Dental Association Class Representative, 3 years. 